\title{
Vaporization and Zonal Mixing in Performance Modeling of Advanced LOX-Methane Rockets
}

\author{
George J. Williams, Jr. ${ }^{1}$ \\ The Ohio Aerospace Institute, NASA GRC, Cleveland, OH, 44135 \\ Benjamin R. Stiegemeier ${ }^{2}$ \\ Vantage Partners, LLC, NASA GRC, Cleveland , OH, 44142
}

\begin{abstract}
Initial modeling of LOX-Methane reaction control $(\mathrm{RCE}) 100 \mathrm{lb}_{\mathrm{f}}$ thrusters and larger, $5500 \mathrm{lb}_{\mathrm{f}}$ thrusters with the TDK/VIPER code has shown good agreement with sea-level and altitude test data. However, the vaporization and zonal mixing upstream of the compressible flow stage of the models leveraged empirical trends to match the sea-level data. This was necessary in part because the codes are designed primarily to handle the compressible part of the flow (i.e. contraction through expansion) and in part because there was limited data on the thrusters themselves on which to base a rigorous model. A more rigorous model has been developed which includes detailed vaporization trends based on element type and geometry, radial variations in mixture ratio within each of the "zones" associated with elements and not just between zones of different element types, and, to the extent possible, updated kinetic rates. The Spray Combustion Analysis Program (SCAP) was leveraged to support assumptions in the vaporization trends. Data of both thrusters is revisited and the model maintains a good predictive capability while addressing some of the major limitations of the previous version.
\end{abstract}

\section{Nomenclature}

$\mathrm{A}^{*} \quad=$ Throat area, in $^{2}$

$\mathrm{A}_{\mathrm{e}} \quad=$ Nozzle exit area, in $^{2}$

$\mathrm{C}^{*}=$ Characteristic velocity, $\mathrm{ft} / \mathrm{s}$

$\mathrm{C}_{\mathrm{F}, \mathrm{PI}}=$ Thrust coefficient (for a perfect injector), $\mathrm{lb}_{\mathrm{f}} / \mathrm{lbm} \mathrm{s}$

$\mathrm{F}_{\mathrm{VAC}}=$ Thrust (adjusted to vacuum ambient conditions), $\mathrm{lb}_{\mathrm{f}}$

$\mathrm{G}=$ Mixture ratio variation factor

$\mathrm{I}_{\mathrm{SP}, \mathrm{VAC}}=$ Specific impulse (adjusted to vacuum ambient conditions), $\mathrm{s}$

$\mathrm{L}^{\prime} \quad=$ Characteristic length of the combustion chamber, in

$\dot{\mathrm{m}}=$ Mass flow rate, $\mathrm{lb}_{\mathrm{m}} / \mathrm{s}$

MR = Mixture ratio, oxydizer to fuel

$\mathrm{ODE}=$ Subscript indicating a value calculated assuming one-dimensional equilibrium flow

$\mathrm{p}_{\mathrm{a}} \quad=$ Ambient pressure, psia

$\mathrm{p}_{\mathrm{e}} \quad=$ Nozzle exit pressure, psia

$\mathrm{p}_{\mathrm{o}}^{*} \quad=$ Effective chamber pressure, psia

TDK = Two-dimensional kinetics code

VIPER $=$ Viscous Interaction Performance Evaluation Routine

$\eta_{\mathrm{C}^{*}}=$ Characteristic velocity efficiency

$\eta_{\text {Isp }}=$ Specific impulse efficiency

$\eta_{\text {MIX }}=$ Mixing efficiency

\footnotetext{
${ }^{1}$ Senior Scientist, OAI, Propulsion and Propellants Branch, 21000 Brookpark Rd., MS 16-1, Associate Fellow.

${ }^{2}$ Aerospace Engineer, Propulsion and Propellants Branch, 3000 Aerospace Parkway, AIAA Member.
} 


\section{Introduction}

$\mathrm{I}_{\mathrm{s}}^{\mathrm{N}}$ $\mathrm{N}$ an effort to provide a higher-performing, more environmentally compatible alternative to hydrazine-based space storable propellants, NASA's Propulsion and Cryogenics Advanced Development (PCAD) project within the Exploration Technology Development Program (ETDP) pursued the demonstration of LOX-methane rocket engines. ${ }^{1,2}$ Integrated main and reaction control propulsion systems utilizing $\mathrm{LOX}-\mathrm{LCH}_{4}$ could provide substantial savings in overall system masses. In addition, the moderately higher performance could enable larger payloads or more demanding maneuvers as the mission architectures develop.

The Aerojet Corporation was contracted to develop and test a $100 \mathrm{lb}_{\mathrm{f}}$ class $\mathrm{LOX}-\mathrm{LCH}_{4}$ reaction control engine (RCE). ${ }^{3}$ Extensive sea-level testing at Aerojet and altitude testing at the NASA Glenn Research Center (NASA GRC) allows one-to-one comparison of the sea level and altitude data. Details of performance characterizations are discussed in separate publications for both sea level and altitude testing. ${ }^{4,5}$ However, trends in observed data are discussed in light of the modeling. A brief discussion of the hardware and the different configurations is provided below. Preliminary modeling of the RCE performance was given by Williams. ${ }^{6}$

The Aerojet Corporation was also contracted to develop and test a $5500 \mathrm{lb}_{\mathrm{f}}$ class $\mathrm{LOX}-\mathrm{LCH}_{4}$ engine as riskmitigation for a potential ascent main engine (AME) for a lunar lander. ${ }^{7}$ The ascent main engine development program was specifically tailored to enable the anchoring of analytical models with engine performance data. Details of performance characterizations are discussed in separate publications for both sea level and altitude testing. ${ }^{8,9}$ A brief discussion of the hardware and the different configurations is provided below. Sufficient data were collected to enable validation of performance models for both configurations. ${ }^{10}$

Numerical modeling conducted at GRC in support of this effort is presented. The objectives of the modeling were to demonstrate the ability to accurately incorporate $\mathrm{LOX}-\mathrm{LCH}_{4}$ kinetics using standard performance codes to predict performance at sea level and to demonstrate the ability to extrapolate altitude performance given sea-level test data. In particular, variation in the trends of specific impulse, $\mathrm{I}_{\mathrm{SP}}$, with mixture ratio, MR, differed significantly from the trends of one-dimensional equilibrium flow (ODE) predictions. As discussed below, these deviations are significant because they impact the design of the injector. The Two-Dimensional Kinetics (TDK) code from SEA has been used successfully in several previous investigations. ${ }^{11,12,13,14}$, In this investigation, the 2004 version of $\mathrm{TDK}^{15}$ and an updated version with a Parabolized Navier Stokes (PNS) solver, the Viscous Interaction Performance Evaluation Routine (VIPER) Version 3.6.2 (updated in 2008) ${ }^{16}$ were used. The VIPER code was developed especially for pressure-fed, high-area-ratio engines. ${ }^{16}$

\section{Experimental Hardware}

\section{A. RCE Thrusters}

Data were collected on the $100 \mathrm{lb}_{\mathrm{f}} \mathrm{RCE}$ thrusters at Aerojet (sea-level ${ }^{3}$ ) and NASA GRC (sea-level and altitude). ${ }^{4,5}$ Altitude testing at NASA WSTF did not yield performance data, but did demonstrate system integration. Aerojet manufactured several injector and thrust chamber configurations for the $100 \mathrm{lb}_{\mathrm{f}}$ RCE. Two of the injectors are modeled. Both consisted of three zones; a core zone, a barrier zone, and a dedicated fuel film cooling (FFC) zone for wall compatibility. The designs differed in that one has $20 \%$ FFC and the other has $30 \%$ FFC. Both were extensively tested at sea level with different thrust chambers, but only the better performing $20 \%$ FFC injector was used during altitude testing.

Table 1 summarizes the hardware modeled in this investigation. The RCE thrust chambers for both sea-level and altitude testing were radiatively-cooled columbium $(\mathrm{Nb})$. Nominally designed for an expansion ratio of 80:1 in space, expansion ratios of 3:1 and 45:1 were fabricated for sea-level and altitude testing, respectively.

Ignition of the engines was accomplished using a torch igniter/spark plug assembly designed to operate at a nominal mixture ratio of approximately 1.8. The integral igniter remained on for the duration of the thruster firing. As the igniter feed line set points were determined by the overall engine operating point, the exact igniter mixture ratio changed slightly with engine test conditions. However, the flow through the igniter was so small, roughly $2.5 \%$ of the total flow, that the impact on overall thruster mixture ratio was less than $1 \%{ }^{4}$

Figure 1 shows photographs of the RCE operating at sea-level (a) and at altitude (b). Both show steady, long duration operation as opposed to short-pulse operation. While the RCE was nominally designed for operating in a series of short pulses, and was characterized extensively at both sea-level and altitude in this regard, modeling of the transient nature of the pulsed tests was beyond the scope of this investigation. 


\section{B. AME Thrusters}

Data were collected on a $5500 \mathrm{lb}_{\mathrm{f}}$ AME designed and manufactured by Aerojet at Aerojet (sea-level) and NASA WSTF (altitude). The engine is designed to operate at a nominal chamber pressure of $250 \mathrm{psia}$ and an overall mixture ratio of 3.0. As with the RCE, the injector consists of three main zones; a core zone, a barrier zone and a dedicated fuel film cooling (FFC) zone for wall compatibility. The nominal engine flow rates (including igniter) are $11.6 \mathrm{lb}_{\mathrm{m}} / \mathrm{s}$ LOX and $3.87 \mathrm{lb} / \mathrm{s}$ methane.

Ignition for the engine is accomplished using a torch igniter/spark plug assembly designed to operate at a nominal mixture ratio of approximately 1.0. Propellant flow to the igniter was drawn from the main run lines and controlled at the entrance to the igniter manifolds by 0.375 in diameter solenoid valves. As the igniter feed line set points were determined by the overall engine operating point, the exact igniter mixture ratio slightly changed with engine test conditions. A custom designed spark plug was used to initiate combustion in the igniter. In all tests conducted in this program, oxygen flow to the igniter was terminated at approximately $0.35 \mathrm{sec}$ into the engine profile while methane was allowed to flow during the entire engine run to preclude hot combustion products from flowing into the igniter body.

There were separate AME ablative combustion chambers for operation at sea level and at altitude. Both thrust chambers had a conically converging design with an upstream contraction ratio of about 2.5 . The expansion of the sea-level chamber, also conical, was to an area ratio of 1.9. The altitude chamber was designed to operate with a radiatively cooled nozzle extension. A Space Shuttle Orbital Maneuvering Engine (OME) nozzle extension constructed of FS-85 columbium was attached to the altitude chamber ablative liner at an area ratio of approximately 14 with the total expansion ratio being about 129:1. The altitude chamber's contour downstream of the throat was contoured to smoothly transition to the nozzle extension. Table 1 also provides a summary of the nominal target geometry and test conditions of the AME altitude engine.

Figure 2 shows the AME operating at sea-level (a) and at altitude (b). Note that the AME was fired vertically downward at WSTF and the image in Fig. $2 b$ has been rotated for the sake of presentation. The AME was designed to operate for several minutes per firing. The radiating nozzle reached a steady thermal condition after about $40 \mathrm{~s}$.

\section{Theory and Modeling}

Thorough discussions of the modules and calculation logic of TDK are available in the literature ${ }^{12,13,15,16}$ and are not repeated here. However, for ease in understanding of the discussions below, a few aspects are revisited. The one-dimensional equilibrium (ODE) module of TDK calculates one-dimensional engine performance using chemical equilibrium conditions throughout the combustion and expansion processes. Boundary layer effects and flow divergence are not incorporated. By convention, the ODE calculation for an engine using a single zone is considered ideal performance. ${ }^{17}$ Radial mixing (zoning), vaporization, total pressure loss, boundary layer losses, and two-dimensional divergence are incorporated as modifications (reductions) in the ODE performance. The TDK module includes boundary layer effects. Without additional constraints on the mixing and vaporization processes, the TDK calculation with boundary layer effects is an approximation to a perfect injector (TDK-PI). ${ }^{17}$

Thrust and specific impulse calculated by TDK and VIPER assume a vacuum exit condition. For comparison to the predicted values, experimental data were "corrected" to vacuum exit conditions by increasing the thrust by $\mathrm{p}_{\mathrm{a}} \mathrm{A}_{\mathrm{e}}$. The ambient pressure was measured in the vicinity of the test and not near the exit plane of the nozzle. The uncertainty introduced by measuring the pressure in this way was very small for altitude testing, but significant for sea-level. However, the sea-level correction is a constant fraction of the overall thrust and its uncertainty should not impact the trends in performance.

Figure 3 compares ODE, TDK-PI, and one-dimensional frozen flow (ODF) contours to the RCE and AME sealevel and altitude data. (SCAP curves are also shown, but are discussed below.) For all cases, the experimental data are, as expected, below the ideal curves, but they also do not follow the trends of these curves. One would expect a significant decrease in performance at lower MR, but this is not observed. Indeed, the performance appears to first order to be largely independent of MR. That this is the trend for both the very small RCE and the relatively large AME suggest that this may be a universal trend for methane thrusters. This trend is not captured through simple application of existing codes such as TDK or VIPER. But, the trend is potentially very significant since there are significant advantages to operating away from the nominal peak performing MR. These include the ability to operate cooler at lower overall MR, reducing the fraction of the fuel needed for a film cooling layer. However, without the ability to accurately predict the dependency of performance on MR (or lack thereof), the design process will be limited to an experiential process which is expensive and currently limited due to the small database of LOX- 
$\mathrm{LCH}_{4}$ thrusters. The following discussion presents the approach taken to make reasonable predictions in a systematic way.

\section{A. Fundamental Parameters}

The following definitions and conventions were used in the analysis of the measured and predicted performance parameters. Conventions used to generate the experimental values, e.g. mass flow rate, and their respective uncertainties are discussed in detail in separate publications. ${ }^{9}$

VIPER does not directly incorporate a total pressure loss during the combustion of the propellants. During both sea-level and altitude testing, the chamber pressure was measured at the face of the injector. However, both performance calculations based on measured values, e.g. $\mathrm{C}^{*}$, and VIPER require the total pressure at the throat, the effective chamber pressure, $\mathrm{p}_{0}^{*}$. To be consistent, the experimental $\mathrm{C}^{*}$ values reported below use the effective chamber pressure assumed in the model.

Because the AME has a conically converging chamber and not a cylindrical chamber with a short converging section, it is inappropriate to apply the standard JANNAF analytical method to estimate the total pressure loss during vaporization and energy addition. The energy and mass addition are occuring at higher velocities and therefore the momentum loss, i.e. the total pressure drop, will be greater. For reference, for the AME geometry the analytical method yields a total pressure drop of $3 \%{ }^{8}$

An approximation used sucessfully in previous investigations utilizes TDK/VIPER to predict the pressure loss. ${ }^{10}$ For the perfect injector approximation (TDK with boundary layer), the total pressure at the throat can be calculated using

$$
\mathrm{p}_{\mathrm{o}}^{*}=\frac{\mathrm{F}_{\mathrm{vac}}}{\mathrm{C}_{\mathrm{F}, \mathrm{PI}} \mathrm{A}^{*}}
$$

where $\mathrm{F}_{\mathrm{vac}}$ is the measured thrust corrected for vacuum and the thrust coefficient, $\mathrm{C}_{\mathrm{F}}$, is the perfect injector value assuming the pressure at the face of the injector as the chamber pressure. This method is most useful for small expansion ratios where the nozzle loss is small compared to the combustor inefficiency. The sea-level chamber with an expansion ratio of 1.9 is ideal. Using this method, an average pressure drop of 5 percent for the AME tests was calculated and used in the remaining analysis for calculation of $\mathrm{p}_{0}^{*}$.

Because the RCE has a conventional cylindrical chamber with a short converging section, it is appropriate to apply the standard JANNAF empirical method to estimate the total pressure loss during vaporization and energy addition. The empirical method suggests a total pressure drop of 1.5 percent. ${ }^{17}$ The pressures used in the modeling when comparing to data were accordingly set to $98.5 \%$ of the measured values independent of the operating point.

Other measured and predicted performance perameters are calculated using the following expressions:

$$
\begin{gathered}
\mathrm{F}_{\mathrm{vac}}=\mathrm{F}_{\mathrm{MEAS}}+\mathrm{p}_{\mathrm{a}} \mathrm{A}_{\mathrm{e}} \\
\mathrm{C}^{*}=\frac{\mathrm{p}_{\mathrm{o}}^{*} \mathrm{~A}^{*}}{\dot{\mathrm{m}}} \\
\mathrm{I}_{S P, \mathrm{vac}}=\frac{\mathrm{F}_{\mathrm{vac}}}{\dot{\mathrm{m}}} \\
\eta_{\mathrm{C}^{*}}=\frac{\mathrm{C}^{*}}{\mathrm{C}_{\mathrm{ODE}}^{*}} \\
\eta_{\mathrm{Isp}}=\frac{\mathrm{I}_{\mathrm{SP}, \mathrm{vac}}}{\mathrm{I}_{\mathrm{SP}, \mathrm{vac}, \mathrm{ODE}}}
\end{gathered}
$$

\section{B. Contours}

The contour of the thrust chamber is input into VIPER in two sets, one upstream and one downstream of the throat. The upstream section is defined by characteristic parameters such as the contraction ratio and L-prime. The downstream region is specified by a matrix of points corresponding to the expansion region. The altitude expansion conforms to an $80 \%$ bell, however the sea-level expansion is a simple cone. The approximations of both configurations agree well with hardware line drawings.

The throat area was measured as a matter of course between tests. Consistent, cold values for both the AME and RCE were used in Eqns. 1 and 3. Cold values for $A_{e}$ were also used. Because $\mathrm{Nb}$ has a very low coefficient of 
thermal expansion - and the ablative of the AME an even smaller coefficient, the enlargement of the throat area during operation is likely negligible. For a throat temperature around $1600^{\circ} \mathrm{R}$, the RCE's throat area will increase by roughly 1 percent. While the variation in throat area could be incorporated into the modeling as a function of $\mathrm{MR}_{\mathrm{FFC}}$, it was not. In was included in the calculation of $\mathrm{C}^{*}$ which set the effective chamber pressure.

\section{Radial Variation in Mixture Ratio}

Radial variation in mixture ratio can be modeled in VIPER by establishing stream-tube "zones." For each zone, the mixture ratio and fraction of total mass flow are specified. The zones can be allowed to mix. If they do not mix, the gradients between zones can be large. However, the PNS solver in VIPER removes the zones and large gradients can result in computational instability. Therefore, transitional regions are incorporated into the VIPER model with low mass flow fractions to ensure relatively smooth computation.

The zones are defined by the primary regions of the injector: core, boundary zone, and fuel film cooling (FFC). Design calculations and cold flows conducted by Aerojet allow approximations of the MR near the face of the injector and are characterized by the percentage of the fuel in each zone. In this simple approach, the zone near the wall is assumed to entrain some oxygen into the FFC fuel flow. The amount is correlated with the cold flow data as well as with wall temperatures seen during testing. All zonal MR scale with the overall MR. The oxygen flow rates and MR for the other zones are then adjusted to maintain mass conservation given total flow rates and an overall mixture ratio.

Unlike in TDK, the zonal variations in the region upstream of the throat are not maintained in the expansion in VIPER models. Instead the zones are allowed to mix, and the entirety is modeled as one flow for the final performance prediction. This mixing results in increased reactions near the throat and a slight shift towards equilibrium flow for VIPER predictions relative to TDK predictions.

The contribution of the local (zonal) MR to the overall performance of the engine will depend on the amount of flow in the zone and the degree to which the zone is at higher or lower performance than the mean MR. To illustrate the impact of radial MR variation for a model with $\mathrm{N}$ zones, the MR zone factor has been defined as

$$
G=\sum_{i=1}^{N} \frac{\dot{m}_{l}}{\dot{m}} \frac{I_{S P, P I}^{M R i}-I_{S P, P I}^{\overline{M R}}}{I_{S P, P I}^{\overline{M R}}}
$$

where, the $\mathrm{I}_{\mathrm{SP}, \mathrm{PI}}$ is the TDK calculated perfect injector (TDK-PI) vacuum specific impulse and MR-bar is the nominal (average) MR for the entire injector. For a single zone, $\mathrm{G} \equiv 0$. Dedicating $30 \%$ of the fuel to FFC resulted in large (> 1.5x nominal) MR in the core flows of that injector. Reducing this to around $20 \%$ yielded MR perhaps $10 \%$ greater than the nominal MR. ${ }^{10}$ MR variations and flow fractions consistent with the Aerojet measurements are assumed throughout the analysis. In addition to the cold flow measurements which provide at least a relative MR distribution across the face, the boundary layer MR can be inferred from the wall temperature.

It should be noted that there are other options in both TDK and VIPER to accommodate radial mixing. In particular, the VARMIX option will allow a limited amount of mixing between zones, entrainment, to occur upstream of the throat. The ENTRAINMENT option is more versatile and is used instead to model the vaporization and mixing and to model the interaction of the barrier elements with the FFC zone. The last results in the increase of the MR of the FFC zone along the length of the chamber to one which yields the observed wall temperatures at the throat. Since an MR=0 would be computationally unstable, an initial MR for the FFC zone is assumed. This value is scaled with overall MR and tied to the injector design. For the 30\% FFC injector and for an average MR of $2.5, \mathrm{MR}_{\mathrm{FFC}}$ is 0.5 at the injector and increases via entrainment to 1.3 at the throat. $43 \%$ of the fuel is assumed to be in the barrier elements of which one-third is entrained into the wall zone. For the $20 \%$ FFC injector $\mathrm{MR}_{\mathrm{FFC}}$ is initially 0.6 transitioning to 1.6 at the throat.

\section{Vaporization}

Vaporization can be incorporated into VIPER either by specifically allowing for droplet vaporization via the Spray Combustion Analysis Program (SCAP) routine ${ }^{18}$ or by controlling the availability of a reactant for combustion as a function of distance from the injector face. In the latter, all flow is assumed to begin as cold gas flow. Because of the very small droplets being considered in this investigation and because of the variation in injector element design across the face of the injector, the latter method has been incorporated. However, as a tool, the SCAP routine can be used to generate vaporization curves for different operating conditions. A third option of a rigorous vaporization and combustion model which can then serve as an input into VIPER was not pursued. We deemed that 
the uncertainties associated with the assumptions of that approach threatened to mask what is truly a macroscopic adjustment of VIPER.

One way of modeling the availability of propellants is to entrain species as a function of distance from the face of the injector. In effect, this entrainment consists of another layer of zoning in which, as with the FFC zone discussed above, two flows are mixed to give a final MR. In this case, each of the non-FFC zones is divided into an initial flow and a co-propagating flow which is "added" to the original flow. By adding energy and momentum to the flow, the final zonal flow rate is established.

Three effects are captured through the vaporization model which is applied to each zone within the model except the FFC zone. One is the overall vaporization of the propellants as a function of distance from the injector face. The rate of entrainment for vaporization is specified as a function of axial position normalized to the throat radius as is shown in Figure 4a. The curve is based on a Priem-method estimation of vaporization assuming a standard distribution of droplets sizes ${ }^{19}$.

The second effect is the delayed vaporization of the methane relative to the LOX. The initial flow is assumed to have a lower MR than the average zonal MR and the entrained flow is assumed to be higher. For nominal inlet conditions, it is assumed that $50 \%$ of the $\mathrm{LCH}_{4}$ is vaporized at the beginning of the model while only $25 \%$ of the LOX is. The entrained flow then adds the remaining $75 \%$ of the LOX and $50 \%$ of the $\mathrm{LCH}_{4}$ as it combusts. The differences in temperature and momentum for the two flows result in a significant decrease in performance for most cases, especially for high overall MR. However, at low overall MR, the initial mixture ratio in the zone is close to stoichiometric and the added flow, being mostly light, does not detract as much. This approach is consistent with data as will be discussed below. If the two flows are assumed to be in equilibrium (i.e., fully reacted) as they are introduced, the differences in the MR would be very high, the chemistry of the flow would be wrong, and the temperature would be too high. To maintain "reasonable" MR and to allow for extended combustion along L-prime, some of the $\mathrm{LOX}$ and $\mathrm{LCH}_{4}$ are introduced as unreacted species in the initial and entrained flows, respectively. In cases where either or both of the propellants are assumed to enter the chamber as gases, the gaseous propellant is introduced as a non-equilibrium component of the initial flow to ensure stability of the entrainment option.

The third effect of the vaporization model is capturing the higher than expected performance of methane at low MR. LOX- $\mathrm{LCH}_{4}$ thrusters of very different sizes have exhibited a strong deviation from the trends suggested by TDK-type models. As mentioned above, this is partly explained by the variation in MR across the face of the injector. However, this flattens and shifts the peak performance to lower MR while largely maintaining the same parabolic trend. One possibility for the manifestation of a completely different trend is the impact of the change in momentum ratios of the injector elements with MR. An attempt to empirically capture the change through varying the vaporization rate proved successful in modeling the Aerojet AME. ${ }^{10}$ Figure 4 shows schematically the difference in vaporization curves. Figure 4a compares extended and shortened profiles with a nominal profile. Figure 3b compares the SCAP vaporization profiles for MRs of 2.0 and 3.5. Note that the LOX vaporization is predicted to "extend" at the higher MR as is assumed in this effort. The $\mathrm{LCH}_{4}$ is predicted to have negligible dependence on MR. The combined effect is consistent with the approach shown in Fig 4a. Figure 4c shows the impact of changing the vaporization curve on $\eta_{C *}$. Because the injector elements are not only different in size but also in kind between the AME and the RCE thrusters, the change in vaporization with MR was retailored for sealevel data for the RCE thrusters.

\section{E. Kinetics}

Kinetic equations and rates used in TDK and VIPER were modified to include a methane combustion set of reactions consistent with the NIST recommended rates for chemical reactions. ${ }^{20}$ Order of magnitude variations in the controlling rates had negligible impact on the predicted performance. However, entrained $\mathrm{CH} 4$ tends to be treated as an inert (like soot) in TDK/VIPER so a reasonable set of rates was needed to override the default. One explanation for the tendency of TDK to under predict altitude performance data given agreement with sea-level performance data is that the methane kinetic rates are too high resulting in over prediction of sea-level performance (which is "corrected" by adjusting other things as discussed above) and eliminating additional equilibration through the early stages of the expansion.

Low temperature specific gravities and specific heats were specified for all of the reactants. As long as the reactants remained liquid leaving the injector, sensitivity to their temperature was negligible, $(<0.1 \mathrm{~s}$ in ISP for a 20 deg $\mathrm{F}$ change in propellant temperature). For gaseous propellants, changes were made to the initial enthalpies, densities, and temperatures in the initial input deck as well as in the ENTRAINMENT modules. These changes produced a noticeable effect, 1 or $2 \mathrm{~s}$ of increased performance. However, the effect is additive to the change in vaporization assumptions given a gaseous reactant. 


\section{F. Boundary Layer}

A major advantage of the VIPER code over the TDK code is the rigorous boundary layer calculation associated with the PNS solver. Comparison of the boundary layer thicknesses and losses is given below in the discussion of altitude data. The differences in the short sea-level nozzle were negligible as is noted.

In both codes, a fully kinetic boundary layer is assumed. There is little computational time impact from this assumption. Since the boundary layer is allowed to transition to turbulent when the Reynolds number reaches 460 , a fully turbulent boundary layer is assumed throughout the length of the thrust chamber.

\section{G. Wall Temperature}

Wall temperatures can be calculated by or input to the VIPER model for both the RCE and AME thrusters. Data were collected which allows specification of the wall temperature to a rough degree. For the RCE, Figure 5a compares the temperature profiles for an average MR of 2.5 for the $20 \%$ FFC case estimated by Aerojet CFD modeling, estimated via color-temperature at both sea-level and altitude, and the profile generated by TDK for a $\mathrm{MR}_{\mathrm{ffc}}$ of 1.6. Note the remarkably good agreement. Because of the good agreement, a radiative wall condition was assumed for all cases and MRffc was scaled with overall MR and with the percent FFC.

For the AME, Figure 5b compares temperature profiles calculated for $\mathrm{MR}_{\mathrm{ffc}}=1.5$ and 1.8 , an Aerojet CFD projection, and an estimate from color temperature. Unlike for the RCE, the color temperature was limited to the radiating wall of the nozzle extension. A long duration, $110 \mathrm{~s}$, test was run at sea-level with an MR=3.0. This test provided sufficient char information on the ablative for Aerojet to estimate the steady-state surface temperatures. This data is included in Fig. $5 \mathrm{~b}$ as the Aerojet projection. The primary difference is in the upstream region. The image-based profiles (color temperature) of the nozzle extension after $40 \mathrm{~s}$ of operation are anchored to pyrometer data near the transition to the nozzle extension (indicated in the Figure by a dashed line). Specifying this predicted wall temperature profile increased the predicted performance over the original assumption (a wall MR of 1.4) by about $2 \mathrm{~s}$ in $\mathrm{I}_{\mathrm{SP}}$. A wall MR of 1.5 was used along with a specified wall termperture based on the char measurements and nozzle imaging to match the sea-level data and to predict data at altitude. A composite of these profiles yields a curve with the open circles in the figure. The distribution given by the thin line was used as a baseline for the MR = 3.0 operating point. The $\mathrm{MR}_{\mathrm{ffc}}$ varied with $\mathrm{MR}$ and the wall temperature profile was scaled accordingly.

\section{H. Summary of the Method}

Beginning with the TDK-PI model (in VIPER), a radial variation in mixture ratio was added. This variation was based on the aperture geometry of the different injectors as well as Aerojet's estimates of flow splits for an MR=2.5. The MR in each of the zones was then scaled with the desired average MR while conserving mass in the total flow rate. The chamber pressure was set to $p_{0}^{*}$. and the vaporization was adjusted to match the resulting $\eta_{C^{*}}$. Once enough data were in hand to validate these models, in principle the vaporization profile could be set a priori.

Because of the uncertainties associated with both sea-level and altitude data (from scatter independent of systematic uncertainties) it is difficult to use either set of data as an absolute reference for anchoring the model to predict the other set. Never-the-less, except for the nozzle contour itself, all settings established to model the sealevel data were used to predict altitude performance. This approach does not play to the strength of VIPER since it, like TDK, is designed primarily to model the kinetic expansion nozzle flow and not the combustion itself. Validating an approach to approximating the combustion processes is intended to strengthen the applicability of VIPER to development of new thrusters.

\section{Results}

\section{A. Comparison of Numerical Predictions to RCE Sea Level Data}

The RCE was tested over a large range of MR and Pc at Aerojet. The majority of this testing was with the Lprime used in altitude testing and only these data are discussed here. The test configuration, engine, and performance data are discussed in detail in Robinson. ${ }^{3}$ Modeling of different L-primes is discussed in Williams. ${ }^{6}$ Table 2 provides a summary of the sea-level data and predictions for those points. Only a subset of data collected are in the Table.

Figure 6 compares the predicted and measured specific impulse for the sea-level testing of both the $20 \%$ and $30 \%$ FFC sea-level chambers. Note that the VIPER curves fall in the middle of the data spreads capturing their respective trends. There is good agreement with the data at low MR. Usually there is very poor agreement in this 
region, but the modification of the axial mixing efficiency appears to capture the trend. All of the discussion regarding agreement of prediction and measurement should be understood in the context of the uncertainties associated with both. An uncertainty of \pm 2 percent ( $\pm 5 \mathrm{~s}$ in $\mathrm{I}_{\mathrm{SP}}$ ) is estimated for the sea-level data. Thus the band of uncertainty captures the entire range of measured and predicted data. Within the predictions themselves, there is considerable, perhaps even greater, uncertainty as suggested by the above discussions. Regardless, the specific impulse predictions and measurements lie within $2 \%$ of each other and appear to follow the same trends.

Figure 7 shows that the measured and predicted thrust are within $1 \%$ of the each other. Figures 8-9 compare the predicted and calculated $\mathrm{C}^{*}$ and $\mathrm{I}_{\mathrm{SP}}$ efficiencies. Note that all trend up at low MR. For both injector designs, the entrainment/vaporization rate within a zone was determined by the MR for that zone. In this respect, the same assumptions used for one injector were shown to be consistent with the other. Because the zone-to-zone MR variation of the 20\% FFC RCE was smaller than that for the 30\% FFC RCE, the impact of the assumptions associated with the vaporization model, in particular with respect to accommodating changes in momentum ratios as MR decreases, is more pronounced. While the assumptions capture the observed performance well, more investigation is required to determine if this is the best or the most appropriate approach.

\section{B. Comparison of Numerical Predictions to RCE Altitude Data}

The 20\% FFC RCE with a 45:1 nozzle was tested over a range of MR and inlet temperatures at the Altitude Combustion Stand (ACS) facility at NASA GRC. The test configuration, engine, and performance data are discussed in detail in Marshall. ${ }^{4}$ The exit pressure of the nozzle was nearly exactly matched to that of the test chamber resulting in a negligible thrust correction. A region of significant non-luminosity is evident at the exit of the thruster between the core flow and the nozzle wall. This "cool" region is likely a combination of boundary layer displacement and film cooling. While there were no in-situ diagnostics to measure this region, images suggest the thickness of the non-luminescence to be roughly 0.35 -inches. The VIPER code predicts a boundary layer thickness of 0.1 -inch at the exit, but it also predicts a cool region of gas $(300 \mathrm{deg} C)$ extending 0.25 -inches into the flow. Coupled with the reasonable approximation to the observed wall temperature, the agreement in boundary layer thickness suggests that the VIPER model is capturing the boundary effects well.

The radial MR variation assumed in the sea-level cases was carried over to predict the altitude performance. Axial mixing and thereby $\eta_{C^{*}}$ was maintained as a function of MR from the sea-level data. Following this convention, it is possible to evaluate the extension of sea-level data to altitude data. Indeed, differences in the predicted performance might then be attributed to the accuracy of the expansion modeling and not to the modeling of the combustion chamber.

Figure 10 compares the predicted and measured specific impulse for the altitude testing for nominal and "coldcold" inlet conditions. These two categories of inlet conditions are considered together since the impact due to enthalpy differences is small. The predicted specific impulses are within $1 \%$ of the measured values. There is a 3.5 to $4 \%$ uncertainty in the measured values $( \pm 17 \mathrm{~s})$ and the uncertainty in the predicted values is at least as large given the assumptions regarding mixing.

Figure 11-13 compare the predicted and measured thrust, $\mathrm{C}^{*}$ efficiency and $\mathrm{I}_{\mathrm{SP}}$ efficiency, respectively. There is still very good agreement. Note that the two efficiencies no longer follow the same trend which reflects the impact of the larger nozzle. As expected, there are greater nozzle-induced losses in $\eta_{\text {Isp }}$ for the altitude cases.

Table 3 provides a summary of the altitude data and predictions for those points. Only a sample of the altitude data and predicted values are tabulated here. Note that there is generally good agreement between the experimental and predicted values, though the differences are higher than the data and calculations for sea-level operation. In part this results from a "normalizing" of the model to the sea-level data.

\section{Comparison of Numerical Predictions to AME Sea-level Data}

The atmospheric chamber was tested at sea-level over a large range of MR and $\mathrm{P}_{\mathrm{C}}$ at Aerojet. As with the RCE, the majority of this testing was with the L-prime used in altitude testing and those are the data discuessed here. The test configuration, engine, and performance data are discussed in detail in Robinson. ${ }^{8}$ Discussion of predictions of performance with other L-primes and nozzle configurations is given in Williams. ${ }^{10}$ Table 4 provides a summary of the atmospheric data and predictions for those points. Only a subset of data collected are in the Table.

Figure 14 compares the predicted and measured specific impulse for the atmospheric testing. Note that there is good agreement across the entire range of MR. As with the RCE, the modification of the vaporization rate and the axial mixing efficiency appears to capture the experimental trend. All of the discussion regarding agreement of prediction and measurment should be understood in the context of the uncertainties associated with both. An uncertainty of \pm 2 percent ( $\pm 5 \mathrm{~s}$ in $\mathrm{I}_{\mathrm{SP}}$ ) is estimated for the sea-level data. Thus the band of uncertainty captures the 
entire range of measured and predicted data. Within the predictions themselves, there is considerable, perhaps even greater, uncertainty as suggested by the above discussions. Regardless, the specific impulse predictions and measurements lie within $1 \%$ of each other and now appear to follow the same trends.

Figure 15 shows that the measured and predicted thrust are also within $1 \%$ of the each other. Indeed, there is remarkable agreement between the predicted and measured values. VIPER calculates the mass flow rate given an effective chamber pressure which has been set in the model to the value of each experimental point (via Eqn 1). Uncertainties in the thrust measurements are shown by error bars. This uncertainty is more easily quantified than others due to direct measurement. It carries over as a lower bound for the $\mathrm{I}_{\mathrm{SP}}$ calculations.

Figure 16 compares the predicted and calculated $\mathrm{C}^{*}$ and $\mathrm{I}_{\mathrm{SP}}$ efficiencies. Note that all reach minima near the "optimal" MR of 3.0. In the predicted values, and perhaps by inference more than in reality, the collective minimazation results from the release of methane for reaction sooner in the lower MR cases. Within the region of interest (i.e. $2.7<\mathrm{MR}<3.1$ ) there is both good agreement and little variation. However, the values are somewhat lower than one might expect, suggesting that there is room to enhance the performance of the engine through perhaps more than one means.

\section{Comparison of Numerical Predictions to AME Altitude Data}

The altitude engine configuration was tested over a range of mixture ratios at the White Sands Test Facility (WSTF). The test configuration, engine, and performance data are discussed in detail in Stiegemeier. ${ }^{9}$ The same correction for effective chamber pressure is assumed in the calculation of the characteristic velocity and its efficiency. This pressure is used to calculate both measured and projected $\mathrm{C}^{*}$ values. Note in Fig. $2 \mathrm{~b}$ there is evidence of a large boundary layer at the exit of the nozzle but that the flow shows no evidence of shocks from overexpansion. The exit pressure is predicted to be more than a factor of 5 higher than the background pressure during the test. No direct measurement of the boundary layer thickness was made during testing. However, overlap of an in-situ scale to the image suggests that the displacement thickness at the exit of the nozzle is on the order of 1.5 inches. TDK predicts a displacement thickness of 0.6 inches. However, the VIPER code indicates a thickness of 1.4 inches without a significant difference in performance estimation. For both cases, a fully turbulent boundary layer was assumed.

As with the RCE, the radial MR variation assumed in the sea-level AME cases was carried over into the altitude modeling. Axial vaporization and mixing and thereby $\eta_{\mathrm{C}^{*}}$ was maintained as a function of MR from the sea-level data. Following this convention, it is possible to evaluate the extension of atmospheric data to altitude data for the larger engine. Differences in the predicted performance might then be attributed to the accuracy of the expansion modeling and not to the modeling of the combustion chamber.

Figure 7 compares the predicted and measured specific impulse for the altitude testing. The predicted specific impulses are within $1 \%$ of the measured values, but always are slightly underpredicting. The reason for this underprediction is unclear. However, there is again a 2 to $2.5 \%$ uncertainty in the measured values ( \pm 7 to $10 \mathrm{~s})$ and the uncertainty in the predicted values is at least as large given the assumptions regarding mixing. One obvious possibility is the inclusion of ablative material in the plume as "free" propellant which will increase thrust. However, post-test inspection of the liner showed negligible ablation, much less the $5.5 \mathrm{lbm}$ needed to provide the additional flow rate.

Figure 18compares the predicted and measured thrust as a function of MR. Again these follow the same trend due to the nature of the modelling, but are in very good agreement with the measured values.

Figure 19 compares the $\mathrm{C}^{*}$ and $\mathrm{I}_{\mathrm{SP}}$ efficiencies as a function of MR. There is very good agreement between values and trends. Note that the two efficiencies no longer follow the same trend which reflects the impact of the larger nozzle. As expected, there are greater nozzle-induced losses in $\eta_{\text {Isp }}$ for the altitude cases. Table 5 provides a summary of the altitude data and predictions for those points.

\section{Discussion}

Good agreement between measured and predicted performance has been demonstrated. Key to this agreement was capturing $\eta_{\mathrm{C}^{*}}$ in a way that preserved the mass flow rate. The assumptions used in this analysis were selfconsistent, but may have masked the impact of other parameters since significant uncertainty remains in the estimation of the effective chamber pressure, the vaporization rate, and in the radial mixing of the reacting streams. However, the modification of vaporization rates and mixing rates yields trends with MR which now follow experimental data for both small and large thrusters. 
The use of the ENTRAINMENT function in VIPER to incorporate the effects of non-ideal combustion appears to be of value. In addition to capturing the effects of vaporization, it provided a means to decrease the performance in accordance with predicted total-pressure losses associated with energy addition in the combustion chamber. Detailed vaporization and mixing data for elements as a function of MR are needed to extend the predictive capability of this approach.

VIPER appears to offer significant advantages over TDK. These include the ENTRAINMENT capability and a more robust calculation of boundary layer thicknesses. Together, these give a much better prediction of wall temperatures, overall performance, and sensitivity to injector design. In particular, capturing the relatively flat performance curve enables a more accurate assesment of the impact of operating off-stoichiometric MR on performance. Basing a design on the peaks in the TDK-PI curves suggests significantly poorer performance than is observed at the cooler-operating lower MR. The procedures demonstrated in this analysis capture the trends in the observed performance and may allow the designing of injectors to the lower MR with confidence in reasonable performance.

The demonstrated performance of the AME at altitude is a significant improvement over state of the art hypergolic systems. There is roughly a $20 \mathrm{~s}$ increase in specific impulse over the more advanced hydrazine engines and as much as $50 \mathrm{~s}$ above the Shuttle OMS engine. ${ }^{21}$ With the tested injector, the engine could operate for several hundred if not a few thousand seconds before the throat area increased prohibitively. The modeling presented here suggests several approaches to improving the performance. These agree with Aerojet internal analyses which include adjusting the distribution of MR across the face of the injector and optimizing the film cooling layer. These improvements, which are not prohibitive, are projected to yield a several percent increase in overall efficiency.

\section{Conclusion}

Good agreement between measured and predicted performance has been demonstrated using the VIPER code with modified vaporization and mixing profiles as a function of mixture ratio. Predicted values of specific impulse and characteristic exhaust velocity were within 1 percent of the measured values for both a small RCE thruster and a large AME thruster. The agreement shown between the measured altitude data and the projected performance based on sea-level data increases the confidence in making these projections in the future.

Key to achieving the agreement between measured and predicted performance was capturing $\eta_{C^{*}}$ in a way that preserved the mass flow rate. This agreement was achieved primarily by varying the vaporization and mixing rates with MR. In this way, significant deviation from the ODE profiles are achieved and reasonable assessment of performance can be made. This technique, may enable the optimization of methane thrusters to lower MR, which was previously thought to incur a prohibitively low performance.

VIPER appears to offer significant advantages over TDK. It offers several mechanisms for incorporating nonideal combustion. It is possible that a true vaporization model may be incorporated into this as well, but, as shown, the effect is more complex than simple vaporization. In this regard, VIPER offers significantly more flexibility than TDK.

\section{References}

${ }^{1}$ Motil, S., Meyer, M., and Tucker, S., "Cryogenic Fluid Management Technologies for Advanced Green Propulsion Systems," AIAA Paper 2007-343, January, 2007.

${ }^{2}$ Collins, J., Hurbert, E., Rornig, K., Melcher, J. C., Hobson, A., and Eaton, P., "Sea-Level Flight Demonstration and Altitude Characterization of a LO2/LCH ${ }_{4}$ Based Ascent Propulsion Lander," AIAA Paper 2009-4948, August, 2009.

${ }^{3}$ Robinson, P.J., Veith, E.M., Hurlbert, E.A., Jimenez, R., and Smith, T.D., "100-lb $\mathrm{fO} 2 / \mathrm{LCH} 4$ - Reaction Control Engine Technology Development for Future Space Vehicles", 59th International Astronautical Federation, Glasgow, Scotland, United Kingdom, September 29 - October 3, 2008.

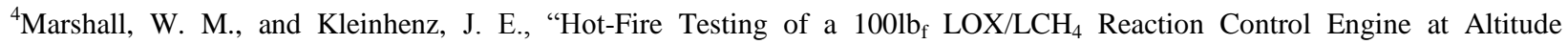
Conditions," JANNAF Propulsion Meeting, May, 2010.

${ }^{5}$ Stiegemeier, B. R., and Marshall, W. M., "Sea-Level Testing of a 100-lb $\mathrm{f}_{\mathrm{f}}$ LOX/Methane Reaction Control Engine," JANNAF Propulsion Meeting, May, 2010.

${ }^{6}$ Williams, G., J., and Stiegemeier, B. R., "Performance Modeling of a Pressure-fed LOX-Methane 100-lb ${ }_{\mathrm{f}}-\mathrm{Cllass}_{\text {Engine," }}$ JANNAF Propulsion Meeting, December, 2011. 
${ }^{7}$ Donahue, B., Grayson, G., Caplin, G., Smith, D. B., and Reiley, K., "Lunar Lander Ascent Module Configuration and Propulsion Studies," IAAA Paper 2009-6406, September 2009.

${ }^{8}$ Robinson, P. J., Veith, E. M., Linne, D. L., and Robinson, J. W., "Design and Development of a 5,500-lb $\mathrm{fOX/LCH4} \mathrm{Ascent}$ Main Engine," $57^{\text {th }}$ JANNAF Propulsion Meeting, May, 2010.

${ }^{9}$ Stiegemeier, B. R., Williams, G. J., Melcher, J. C., and Robinson, J. W., "Altitude Testing of an Ascent Stage LOX/Methane Main Engine," 57 $7^{\text {th }}$ JANNAF Propulsion Meeting, May, 2010.

${ }^{10}$ Williams, G. J., and Stiegemeier, B. R., "Performance Modeling of a Pressure-fed LOX-Methane 5500-lb $\mathrm{f}_{\mathrm{f}}$ Engine," JANNAF Propulsion Meeting, May, 2010.

${ }^{11}$ Smith, T. A., et al., "Comparison of Theoretical and Experimental Thrust Performance of a 1030:1 Area Ratio Rocket Nozzle at a Chamber Pressure of 2413 kN/m² (350 psia),” AIAA Paper 87-2069 (NASA TP-2725), August 1987.

${ }^{12}$ Pavli, A. J., Kacynski, K. J., and Smith, T. A., "Experimental Thrust Performance of a High-Area-Ratio Rocket Nozzle," NASA TP-2720, 1987.

${ }^{13}$ Miyajima, H., and Nakahashi, K., "Performance of a Low Thrust LO2/LH2 Engine with a 300:1 Area Ratio Nozzle," AIAA Paper 83-1313, 1983.

${ }^{14}$ Jankovsky, R. S., Smith, T. D., and Pavli, A. J., "High-Area-Ratio Rocket Nozzle at High Combustion Chamber PressureExperimental and Analytical Validation,” NASA TP-1999-208522, June, 1999.

${ }^{15}$ Nickerson, G. R., et al., "Two-Dimensional Kinetics (TDK) Nozzle Performance Computer Program, Vols I-III, User Manual, NAS8-39048, March, 1993.

${ }^{16}$ Viscous Interaction Performance Evaluation Routine for Two-Phase Nozzle Flows with Finite Rate Chemistry," Viper 3.6 User's Guide, Software and Engineering Associates, Inc., 2004.

${ }^{17}$ JANNAF Rocket Engine Performance Prediction and Evaluation Manual, CPIA-PUBL-246, Chemical Propulsion Information Agency, 1975.

${ }^{18}$ SCAP: Spray Combustion Analysis Program, Software and Engineering Associates, Inc., March, 2005.

${ }^{19}$ Priem, R. J., and Heidmann, M. F., "Propellant vaporization as a Design Criterion for Rocket engine Combustion Chambers," NASA TR R-67, 1960.

${ }^{20}$ Westley, Francis, “Table of Recommended Rate Constants for Chemical Reactions Occurring in Combustion,” National Bureau of Standards, April, 1980.

${ }^{21}$. Neill, T., Judd, D., Veith, E., and Rousar, D., "Practical Uses of Liquid Methane in Rocket Engine Applications," IAC Paper 06-C4.1.01, October, 2006. 
Table 1 Nominal Characteristics of the Aerojet thrusters modeled.

\begin{tabular}{|c|c|c|c|c|}
\cline { 2 - 5 } \multicolumn{1}{c|}{} & \multicolumn{2}{c|}{ RCE } & \multicolumn{2}{c|}{ AME } \\
\hline Configuration & Sea-level & Altitude & Sea-level & Altitude \\
\hline Nominal Thrust, $\mathbf{l b}_{\mathbf{f}}$ & 85 & 100 & 4800 & 5500 \\
\hline Expansion Ratio & 3 & 45 & 1.9 & 128 \\
\hline Chamber pressure, psi & \multicolumn{2}{c|}{175} & \multicolumn{2}{c|}{250} \\
\hline MR Range & \multicolumn{2}{c|}{$1.80-3.25$} & \multicolumn{2}{c|}{$2.00-4.25$} \\
\hline
\end{tabular}

Table 2 A Comparison of Predicted (VIPER) and Measured $^{3}$ Sea-Level RCE Performance.

\begin{tabular}{|c|c|c|c|c|c|c|c|c|c|c|}
\hline \multirow[b]{2}{*}{ MR } & \multirow[b]{2}{*}{$\begin{array}{l}\text { L-prime, } \\
\text { in }\end{array}$} & \multicolumn{3}{|c|}{ Inlet conditions } & \multicolumn{2}{|c|}{ Thrust, $l_{b}$} & \multicolumn{2}{|c|}{$\dot{m}, \mathrm{lb}_{\mathrm{m}} / \mathrm{s}$} & \multicolumn{2}{|c|}{$\mathrm{C}^{*}, \mathrm{ft} / \mathrm{s}$} \\
\hline & & $\begin{array}{l}\text { Tox-inj } \\
\text { deg R }\end{array}$ & $\begin{array}{l}\text { Tf-inj } \\
\operatorname{deg} R\end{array}$ & $\begin{array}{l}\mathrm{p}_{\mathrm{o}}^{*} \\
\mathrm{psia}\end{array}$ & Measured & VIPER & Measured & VIPER & Measured & VIPER \\
\hline 2.00 & 2.5 & 185 & (204) & 185 & 85.5 & 88.0 & 0.328 & 0.348 & 5420 & 5350 \\
\hline 2.40 & 2.5 & 175 & 185 & 186 & 86.0 & 88.0 & 0.322 & 0.350 & 5370 & 5330 \\
\hline 2.50 & 2.5 & (189) & (204) & 189 & 88.8 & 89.0 & 0.339 & 0.354 & 5360 & 5270 \\
\hline 2.65 & 2.5 & 214 & 240 & 191 & 89.4 & 91.0 & 0.343 & 0.340 & 5305 & 5350 \\
\hline 2.80 & 2.5 & 189 & 204 & 189 & 88.7 & 91.0 & 0.340 & 0.360 & 5370 & 5180 \\
\hline 3.13 & 2.5 & 189 & 204 & 189 & 88.7 & 91.0 & 0.340 & 0.363 & 5370 & 5180 \\
\hline
\end{tabular}

\begin{tabular}{|c||c|c||c|c||c|c|}
\hline \multicolumn{1}{|c||}{\multirow{2}{*}{ MR }} & \multicolumn{2}{c||}{ Specific Impulse, $\mathrm{s}$} & \multicolumn{2}{c||}{$\eta_{\mathrm{C}^{*}}$} & \multicolumn{2}{c|}{$\eta_{\text {Isp }}$} \\
\cline { 2 - 7 } & Measured & VIPER & Measured & VIPER & Measured & VIPER \\
\hline 2.00 & 260 & $260 .$. & 0.929 & 0.932 & 0.929 & 0.945 \\
\hline 2.40 & 257 & 259. & 0.895 & 0.899 & 0.886 & 0.906 \\
\hline 2.50 & 262 & 262. & 0.890 & 0.874 & .898 & 0.898 \\
\hline 2.65 & 261 & 260. & 0.885 & 0.884 & 0.890 & 0.887 \\
\hline 2.80 & 261 & 258. & 0.885 & 0.855 & 0.888 & 0.881 \\
\hline 3.13 & 260 & 257. & 0.885 & 0.855 & 0.892 & 0.875 \\
\hline \hline
\end{tabular}

Table 3 A Comparison of Predicted (VIPER) and Measured ${ }^{4}$ Altitude RCE Performance.

\begin{tabular}{|c||c||c|c||c|c||c|c||c|c|}
\hline \multirow{2}{*}{ MR } & \multicolumn{3}{|c||}{ Inlet conditions } & \multicolumn{2}{c||}{ Thrust, $\mathrm{b}_{\mathrm{f}}$} & \multicolumn{2}{c|}{$\dot{m}, \mathrm{lb}_{\mathrm{m}} / \mathrm{s}$} & \multicolumn{2}{c|}{$\mathrm{C}^{*}, \mathrm{ft} / \mathrm{s}$} \\
\cline { 2 - 9 } & $\begin{array}{l}\text { Tox-inj } \\
\text { deg R }\end{array}$ & $\begin{array}{l}\text { Tf-inj } \\
\text { deg R }\end{array}$ & $\begin{array}{l}\mathrm{p}_{\mathrm{o}}^{*} \\
\text { psia }\end{array}$ & Measured & $\begin{array}{c}\text { VIPE } \\
\mathrm{R}\end{array}$ & Measured & VIPER & Measured & VIPER \\
\hline 1.80 & 233 & 222 & 172 & 94.4 & 105 & 0.308 & 0.350 & 5480 & 5330 \\
\hline 2.00 & 222 & 215 & 187 & 103 & 105 & 0.332 & 0.348 & 5400 & 5350 \\
\hline 2.40 & 217 & 217 & 190 & 105 & 106 & 0.344 & 0.350 & 5450 & 5330 \\
\hline 2.55 & 219 & 218 & 189 & 105 & 110 & 0.329 & 0.354 & 5280 & 5370 \\
\hline 2.60 & 219 & 218 & 189 & 105 & 105 & 0.345 & 0.340 & 5300 & 5350 \\
\hline 2.80 & 227 & 220 & 181 & 101 & 100 & 0.350 & 0.360 & 5320 & 5180 \\
\hline \hline
\end{tabular}

\begin{tabular}{|c||c|c||c|c||c|c|}
\hline \multirow{2}{*}{\multicolumn{1}{|c||}{ MR }} & \multicolumn{2}{c||}{ Specific Impulse, $\mathrm{s}$} & \multicolumn{2}{c||}{$\eta_{\mathrm{C}^{*}}$} & \multicolumn{2}{c|}{$\eta_{\text {Isp }}$} \\
\cline { 2 - 6 } & Measured & VIPER & Measured & VIPER & Measured & VIPER \\
\hline 1.80 & 308 & 299 & 0.988 & 0.962 & 0.972 & 0.944 \\
\hline 2.00 & 310 & 300 & 0.939 & 0.945 & 0.916 & 0.910 \\
\hline 2.40 & 307 & 312 & 0.909 & 0.899 & 0.880 & 0.881 \\
\hline 2.55 & 300 & 309 & 0.874 & 0.874 & 0.843 & 0.875 \\
\hline 2.60 & 308 & 310 & 0.876 & 0.884 & 0.862 & 0.863 \\
\hline 2.80 & 296 & 310 & 0.877 & 0.860 & 0.817 & 0.854 \\
\hline \hline
\end{tabular}

12

American Institute of Aeronautics and Astronautics 
Table 4 Comparison of measured ${ }^{8}$ and predicted (VIPER) sea-level performance of the AME engine.

\begin{tabular}{|c|c|c|c|c|c|c|c|c|}
\hline \multirow{2}{*}{ MR } & \multicolumn{2}{|c|}{ Pc, psia } & \multicolumn{2}{|c|}{ Thrust, $\mathrm{lb}_{\mathrm{f}}$} & \multicolumn{2}{|c|}{$\dot{m}, \mathrm{lb}_{\mathrm{m}} / \mathrm{s}$} & \multicolumn{2}{|c|}{$\mathrm{C}^{*}, \mathrm{ft} / \mathrm{s}$} \\
\hline & At Injector & $\mathrm{p}_{0}^{*}$ & Measured & VIPER & Measured & VIPER & Measured & VIPER \\
\hline 2.15 & 259.3 & 242.5 & 3882 & 3887 & 15.68 & 15.74 & 5644 & 5624 \\
\hline 2.29 & 267.5 & 252.2 & 4042 & 4046 & 16.17 & 16.25 & 5694 & 5664 \\
\hline 2.54 & 269.7 & 254.4 & 4080 & 4082 & 16.23 & 16.34 & 5722 & 5683 \\
\hline 2.68 & 271.3 & 255.4 & 4102 & 4100 & 16.50 & 16.43 & 5650 & 5675 \\
\hline 2.84 & 259.4 & 243.3 & 3911 & 3906 & 15.69 & 15.73 & 5660 & 5647 \\
\hline 2.90 & 245.5 & 229.7 & 3694 & 3684 & 14.83 & 14.88 & 5653 & 5634 \\
\hline 2.94 & 268.0 & 251.8 & 4049 & 4044 & 16.31 & 16.29 & 5635 & 5640 \\
\hline 3.00 & 253.9 & 238.3 & 3833 & 3826 & 15.58 & 15.46 & 5582 & 5626 \\
\hline 3.01 & 261.1 & 245.2 & 3945 & 3938 & 15.86 & 15.93 & 5643 & 5617 \\
\hline 3.08 & 275.2 & 259.1 & 4170 & 4162 & 16.84 & 16.86 & 5617 & 5609 \\
\hline 3.14 & 249.7 & 234.3 & 3771 & 3763 & 16.28 & 15.28 & 5254 & 5595 \\
\hline
\end{tabular}

\begin{tabular}{|c||c|r||r|r||r|r|}
\hline \multirow{2}{*}{\multicolumn{1}{|c||}{ MR }} & \multicolumn{2}{c||}{ Specific Impulse, $\mathrm{s}$} & \multicolumn{2}{c||}{$\eta_{\mathrm{C}^{*}}$} & \multicolumn{2}{c|}{$\eta_{\text {Isp }}$} \\
\cline { 2 - 5 } \cline { 5 - 7 } & Measured & \multicolumn{1}{c|}{ VIPER } & Measured & \multicolumn{1}{c|}{ VIPER } & Measured & \multicolumn{1}{c|}{ VIPER } \\
\hline 2.15 & 247.6 & 247.0 & 0.954 & 0.951 & 0.935 & 0.933 \\
\hline 2.29 & 248.7 & 248.9 & 0.950 & 0.945 & 0.925 & 0.926 \\
\hline 2.54 & 251.5 & 249.8 & 0.943 & 0.937 & 0.922 & 0.915 \\
\hline 2.68 & 248.6 & 249.5 & 0.929 & 0.933 & 0.907 & 0.911 \\
\hline 2.84 & 249.2 & 248.4 & 0.931 & 0.929 & 0.909 & 0.906 \\
\hline 2.90 & 249.0 & 247.5 & 0.931 & 0.928 & 0.908 & 0.903 \\
\hline 2.94 & 248.3 & 248.2 & 0.929 & 0.930 & 0.906 & 0.906 \\
\hline 3.00 & 246.0 & 247.6 & 0.922 & 0.929 & 0.899 & 0.904 \\
\hline 3.01 & 248.7 & 247.2 & 0.932 & 0.928 & 0.908 & 0.903 \\
\hline 3.08 & 247.7 & 246.9 & 0.930 & 0.928 & 0.906 & 0.903 \\
\hline 3.14 & 231.8 & 246.2 & 0.872 & 0.928 & 0.850 & 0.903 \\
\hline \hline
\end{tabular}

Table 5 Comparison of measured ${ }^{9}$ and predicted (VIPER) altitude performance of the AME engine.

\begin{tabular}{|c|c|c|c|c|c|c|c|c|c|}
\hline \multirow{2}{*}{ MR } & \multirow{2}{*}{$\mathrm{A}^{*}, \mathrm{in}^{2}$} & \multicolumn{2}{|c|}{ Pc, psia } & \multicolumn{2}{|c|}{ Thrust, $\mathrm{lb}_{\mathrm{f}}$} & \multicolumn{2}{|c|}{$\dot{m}, \mathrm{lb}_{\mathrm{m}} / \mathrm{s}$} & \multicolumn{2}{|c|}{$\mathrm{C}^{*}, \mathrm{ft} / \mathrm{s}$} \\
\hline & & At Injector & $\mathrm{p}_{\mathrm{o}}^{*}$ & Measured & VIPER & Measured & VIPER & Measured & VIPER \\
\hline 2.45 & 11.60 & 256.8 & 241.4 & 5428 & 5376 & 16.05 & 15.80 & 5649 & 5766 \\
\hline 2.56 & 11.48 & 256.5 & 241.1 & 5402 & 5285 & 15.95 & 15.58 & 5676 & 5722 \\
\hline 2.63 & 11.59 & 260.8 & 245.2 & 5539 & 5440 & 16.25 & 15.92 & 5676 & 5746 \\
\hline 2.85 & 11.56 & 261.0 & 245.3 & 5568 & 5461 & 16.29 & 15.93 & 5690 & 5731 \\
\hline 2.86 & 11.42 & 252.0 & 236.9 & 5197 & 5212 & 15.47 & 15.27 & 5649 & 5704 \\
\hline 2.94 & 11.51 & 254.0 & 243.8 & 5415 & 5424 & 15.83 & 15.85 & 5677 & 5700 \\
\hline 3.02 & 11.45 & 256.5 & 241.1 & 5461 & 5341 & 15.93 & 15.59 & 5650 & 5701 \\
\hline 3.06 & 11.54 & 254.0 & 238.8 & 5448 & 5334 & 15.87 & 15.56 & 5676 & 5700 \\
\hline 3.25 & 11.57 & 260.8 & 245.2 & 5616 & 5499 & 16.37 & 16.03 & 5649 & 5697 \\
\hline
\end{tabular}

\begin{tabular}{|r||r|r||r|r||r|r||}
\hline \multirow{2}{*}{\multicolumn{1}{|c||}{ MR }} & \multicolumn{3}{c||}{ Specific Impulse, $\mathrm{s}$} & \multicolumn{2}{c||}{$\eta_{\mathrm{C}^{*}}$} & \multicolumn{2}{c||}{$\eta_{\text {Isp }}$} \\
\cline { 2 - 7 } & Measured & \multicolumn{1}{c|}{ VIPER } & Measured & VIPER & Measured & VIPER \\
\hline 2.45 & 340.3 & 340.2 & 0.939 & 0.936 & 0.934 & 0.933 \\
\hline 2.56 & 340.6 & 339.3 & 0.930 & 0.943 & 0.923 & 0.927 \\
\hline 2.63 & 343.0 & 341.8 & 0.939 & 0.933 & 0.923 & 0.923 \\
\hline 2.85 & 343.8 & 342.9 & 0.939 & 0.933 & 0.910 & 0.913 \\
\hline 2.86 & 341.9 & 341.3 & 0.936 & 0.944 & 0.904 & 0.911 \\
\hline 2.94 & 344.2 & 342.1 & 0.931 & 0.937 & 0.905 & 0.909 \\
\hline 3.02 & 344.8 & 342.5 & 0.938 & 0.937 & 0.903 & 0.906 \\
\hline 3.06 & 344.6 & 342.7 & 0.935 & 0.935 & 0.901 & 0.903 \\
\hline 3.25 & 345.3 & 343.0 & 0.939 & 0.938 & 0.898 & 0.900 \\
\hline
\end{tabular}

13

American Institute of Aeronautics and Astronautics 


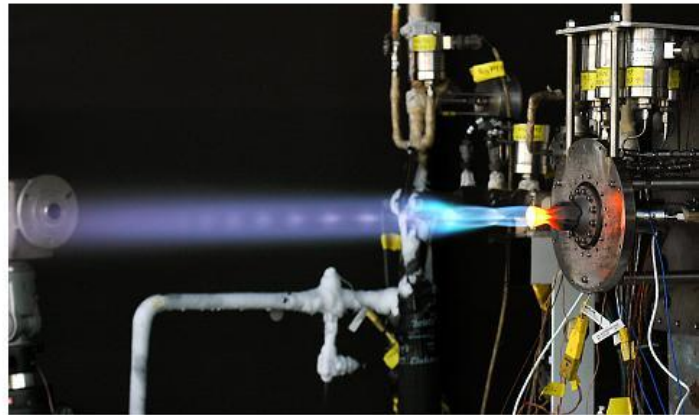

a. Sea-level at Aerojet

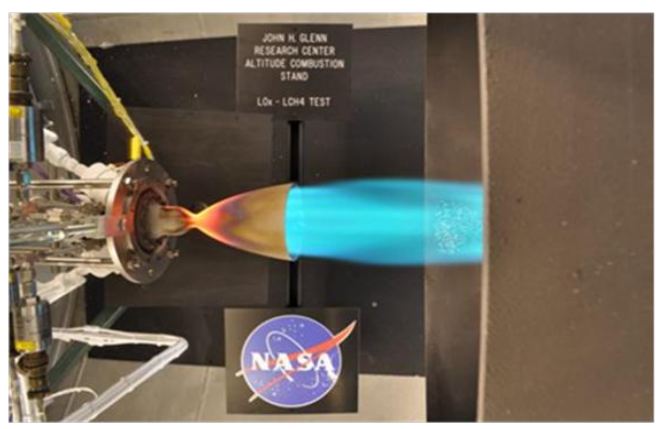

b. Altitude at NASA GRC.

Figure 1 Images of RCE testing.

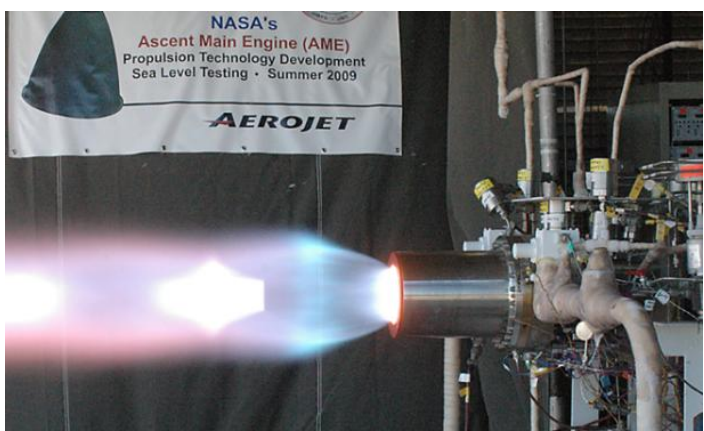

a. Sea-level at Aerojet

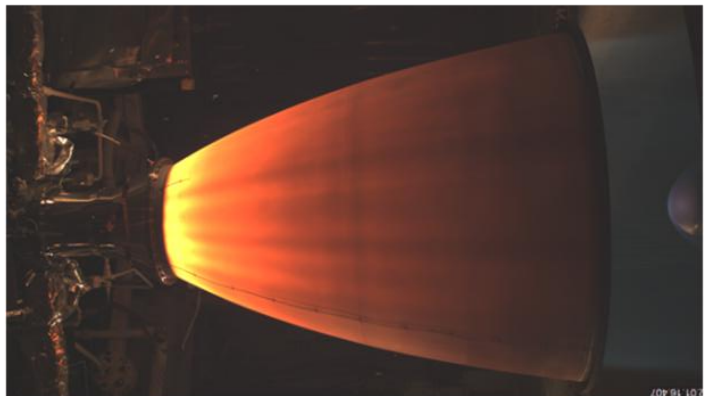

b. Altitude at NASA WSTF.

Figure 2 Images of AME testing.

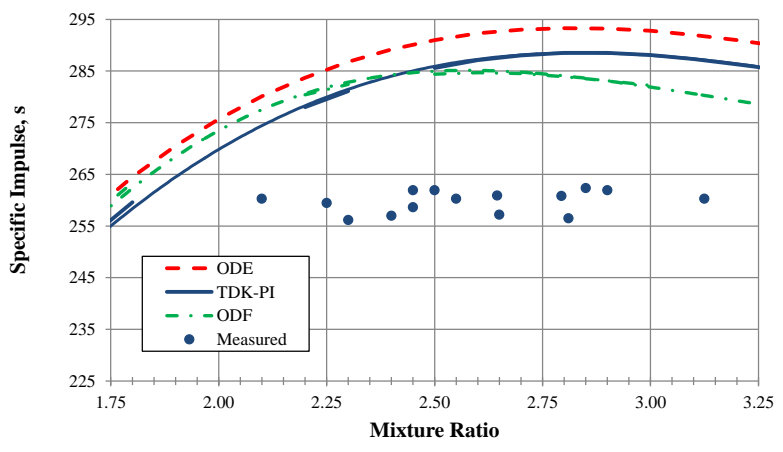

a. Sea-level

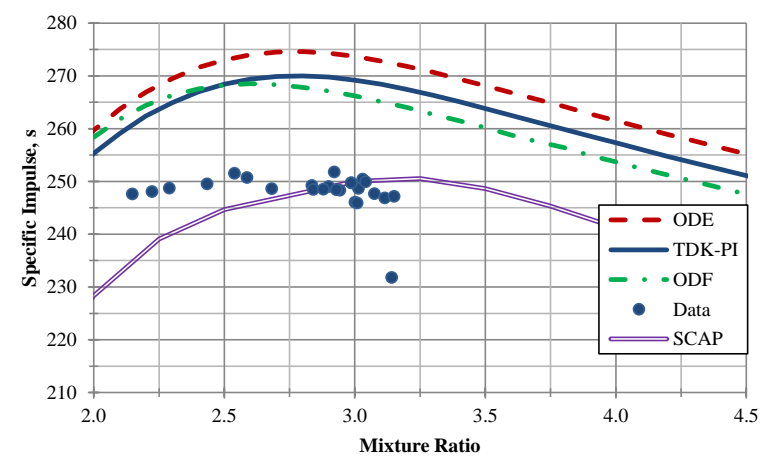

c. Sea-level

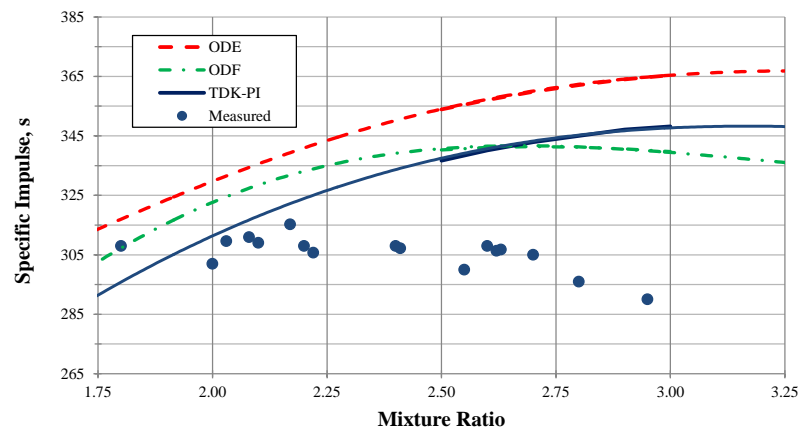

b. Altitude.

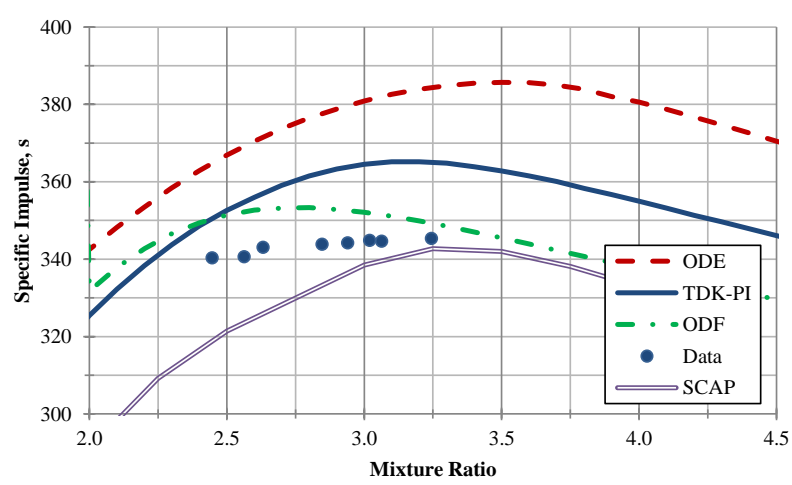

d. Altitude

Figure 3 Comparison of specific impulse trends for the RCE (a-b) and the AME (c-d). 


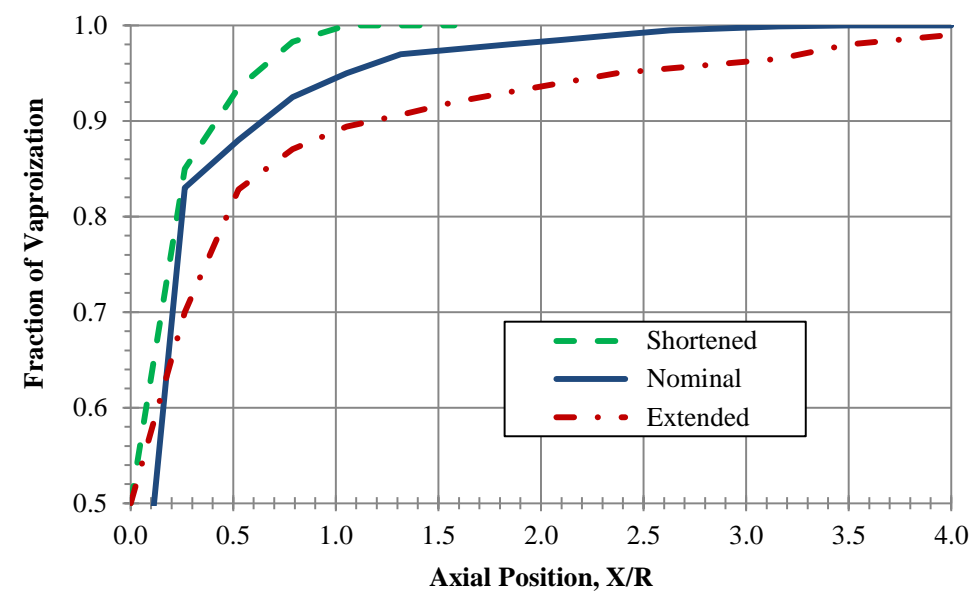

a. Vaporization curves. The "shortened" and "extended" curves arbitrarily increase or decrease the rate of vaporization respectively

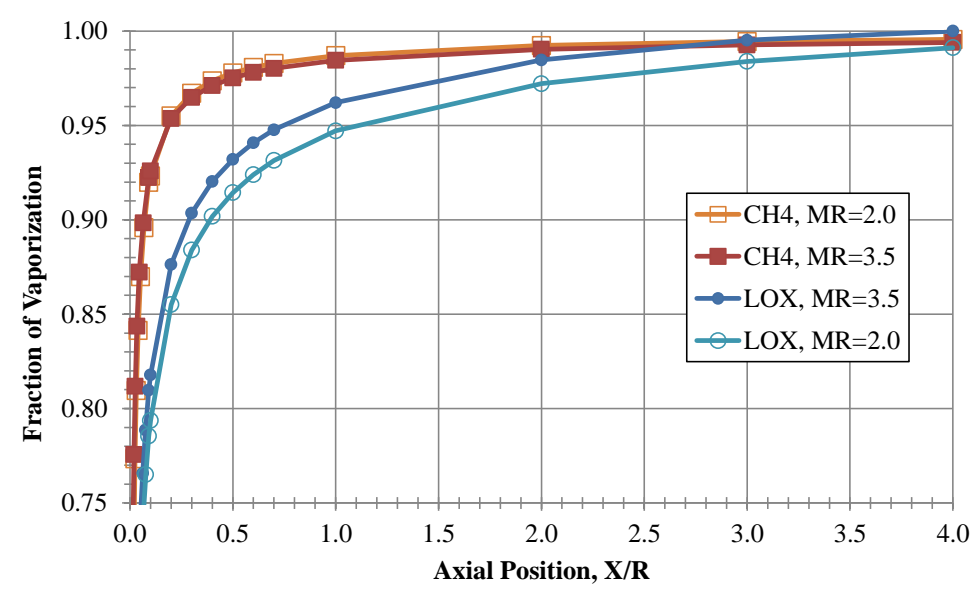

b. VIPER-SCAP calculated vaporization profiles.

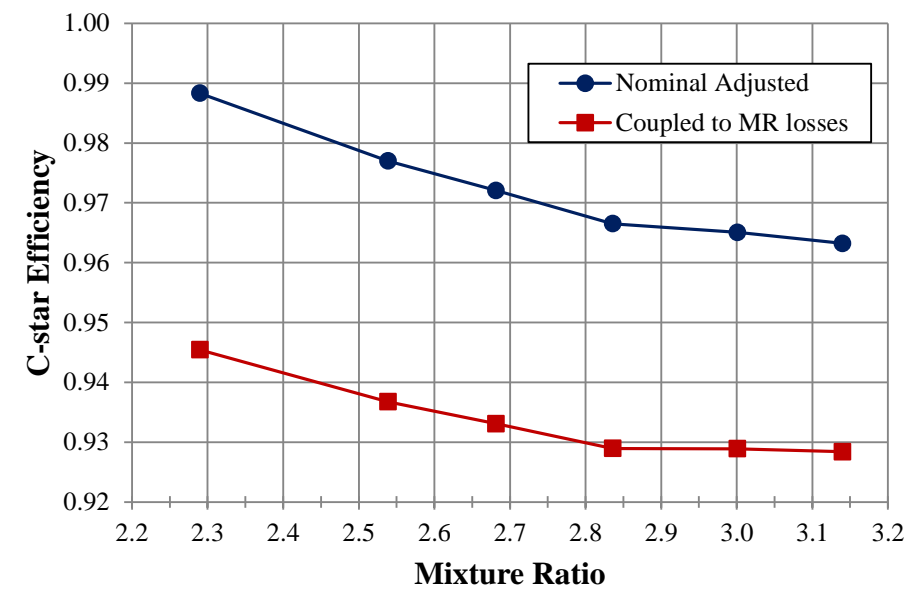

c. $\mathrm{C}^{*}$ efficiency as a function of MR for the AME. The upper curve reflects adjustment to the curve in 4 a for LOX-limited vaporization. The lower curve adds the $C^{*}$ deficit associated with the best-estimate of MR variation across the face of the injector.

Figure 4 Correlation of performance with axial mixing (via vaporization) and radial mixing.

American Institute of Aeronautics and Astronautics 


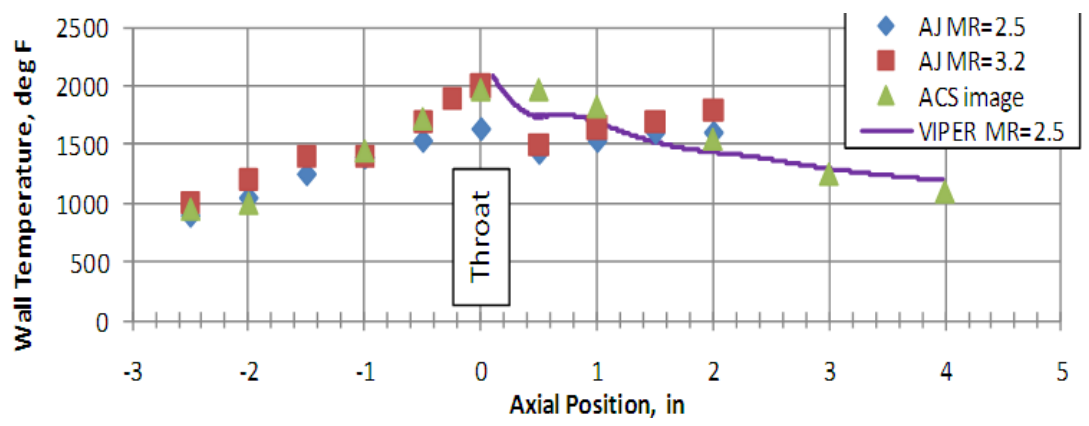

a. RCE wall temperature profiles.

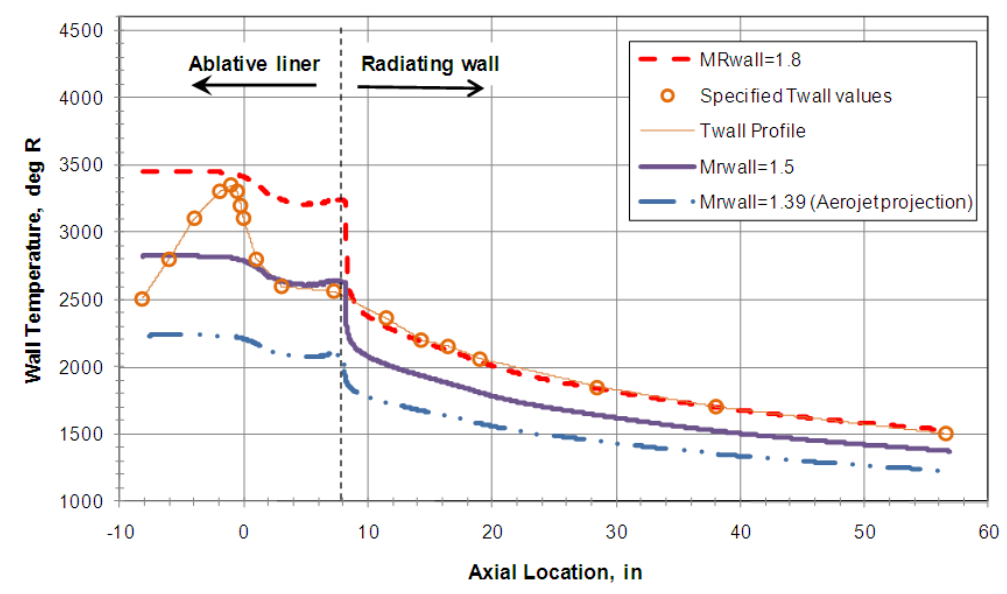

b. AME wall temperature profiles

Figure 5 Comparison of wall temperature profiles.

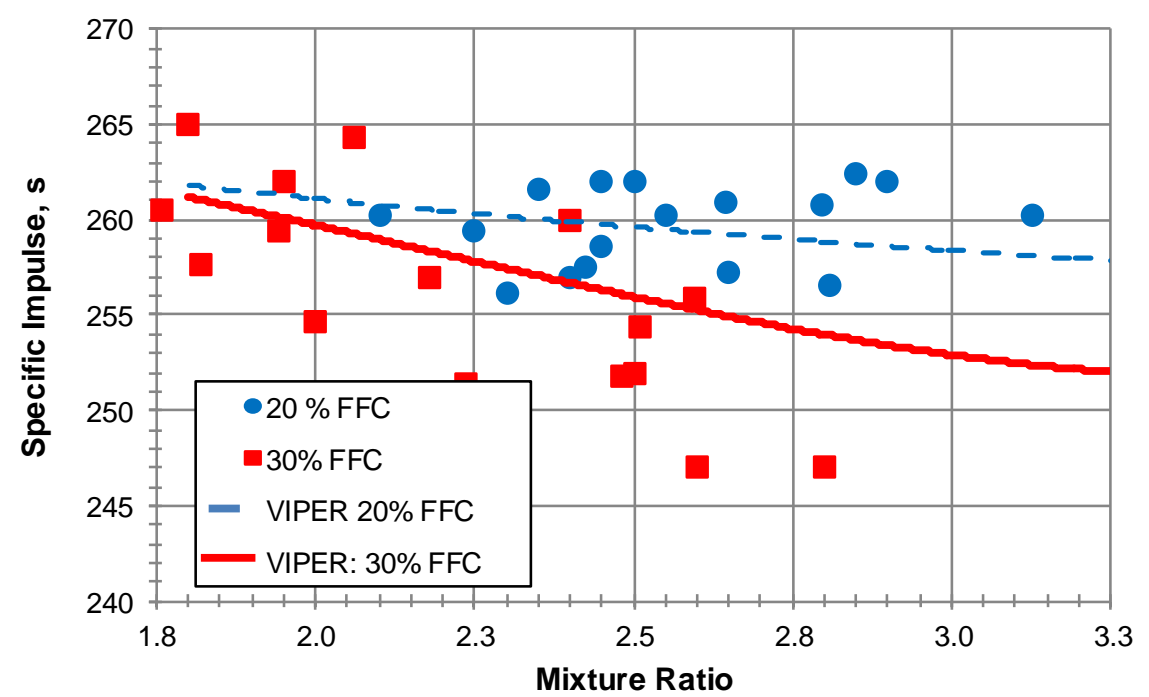

Figure 6 Comparison of predicted and measured ${ }^{3}$ specific impulse for sea-level operation of the $100 \mathrm{lb}_{\mathrm{b}} \mathrm{RCE}$.

American Institute of Aeronautics and Astronautics 


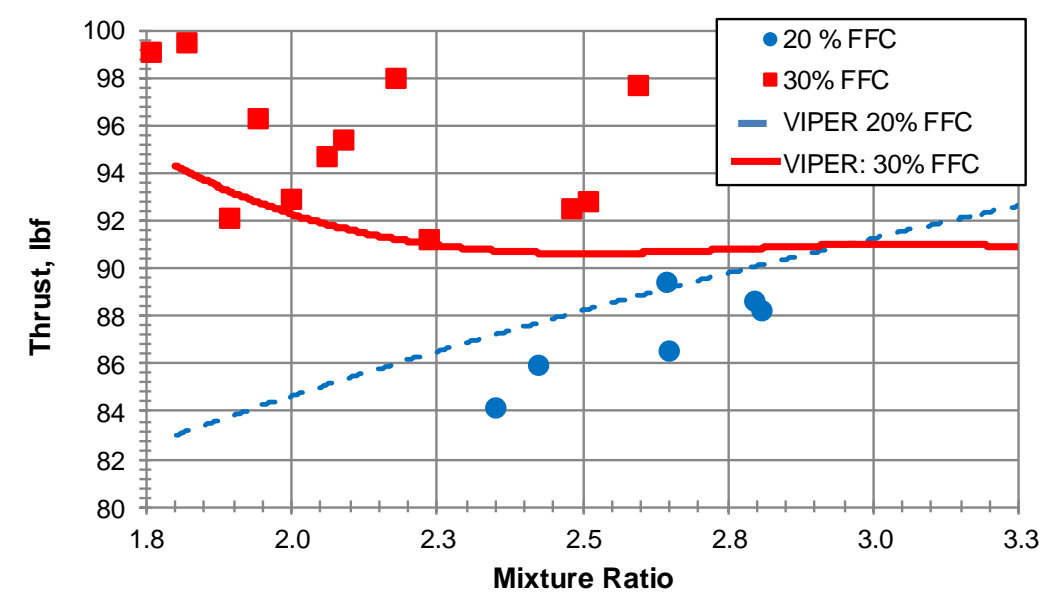

Figure 7 Comparison of predicted and measured ${ }^{3}$ thrust for sea-level operation of the $100 \mathrm{lb}_{b} R C E$. $P_{C}$ was varied to match $P_{C}$ in the data.

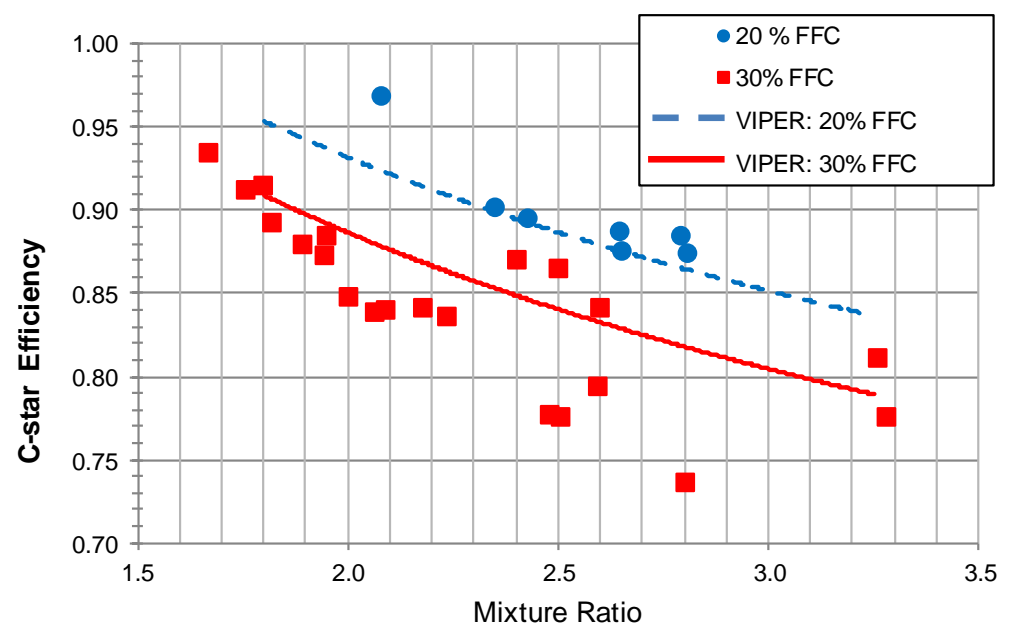

Figure 8 Comparison of predicted and measured $3 \mathrm{C}^{*}$ efficiency for sea-level operation of the $100 \mathrm{lb}_{\mathrm{b}} \mathrm{RCE}$.

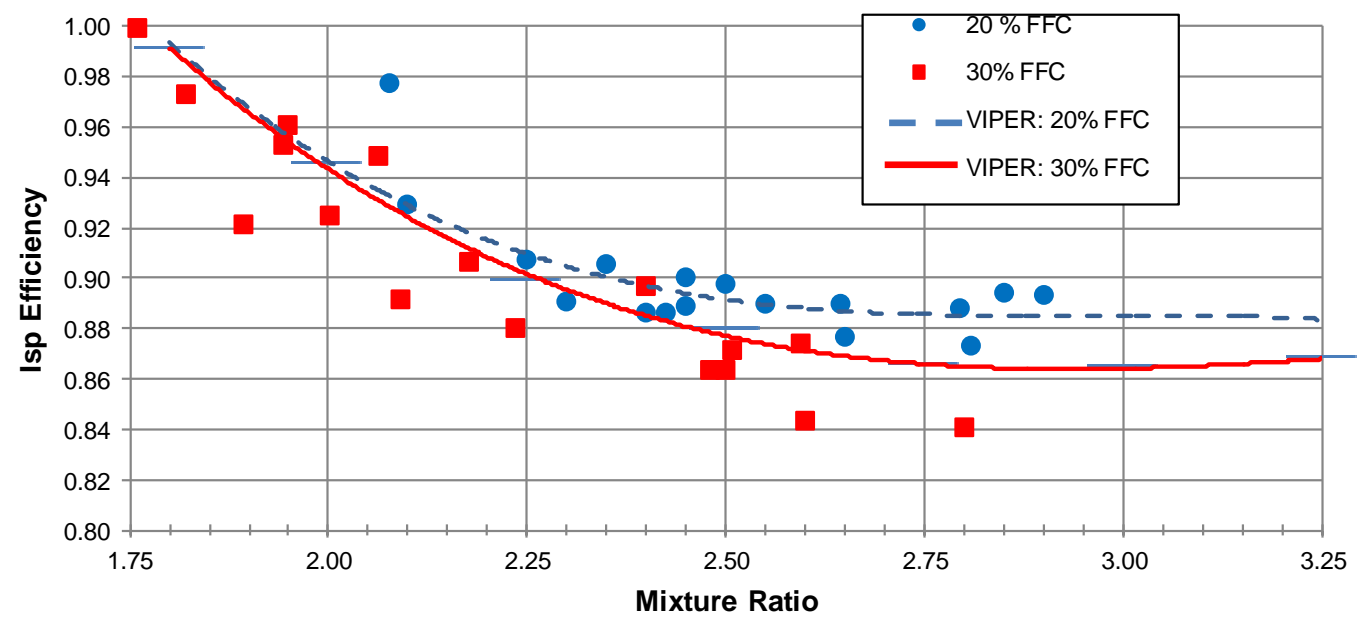

Figure 9 Comparison of predicted and measured ${ }^{3}$ Isp efficiency for sea-level operation of the $100 \mathrm{lb}_{\mathbf{b}} \mathrm{RCE}$. 


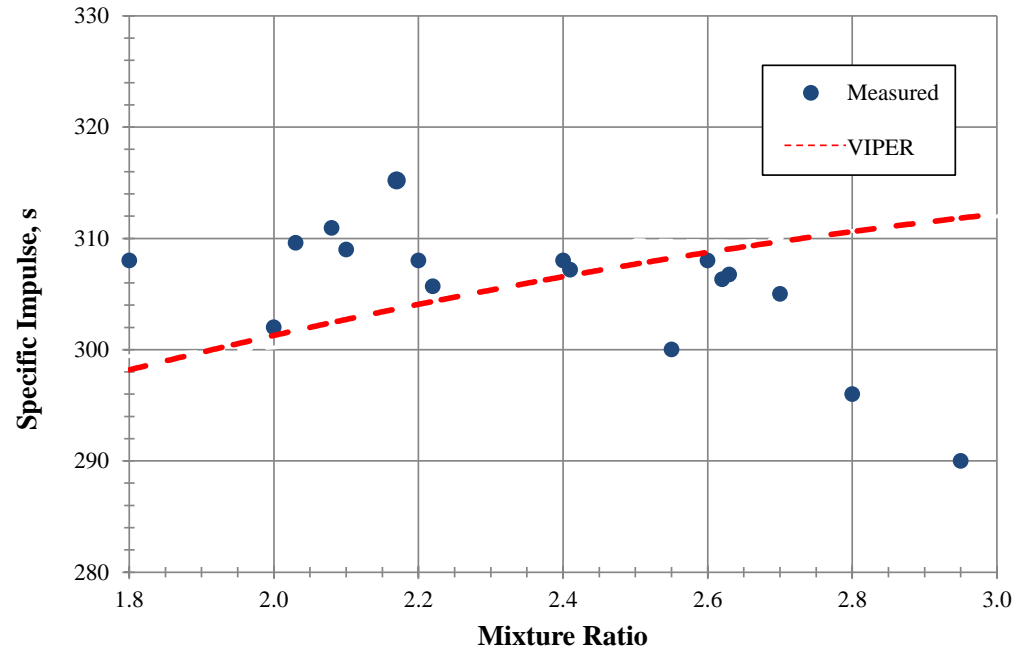

Figure 10 Comparison of predicted and measured ${ }^{4}$ specific impulse for altitude operation of the $100 \mathrm{lb}_{\mathrm{b}}$ RCE. Markers are data for cold to nominal inlet conditions.

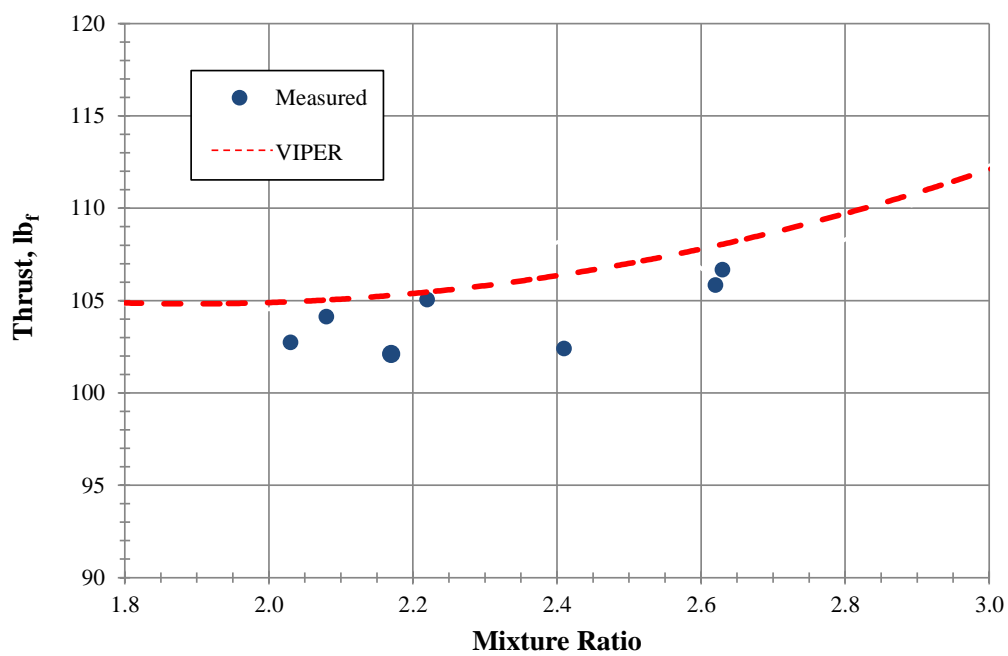

Figure 11 Comparison of predicted and measured ${ }^{4}$ thrust for altitude operation of the $100 \mathrm{lb}_{\mathrm{b}}$ RCE. Markers are data for cold to nominal inlet conditions.

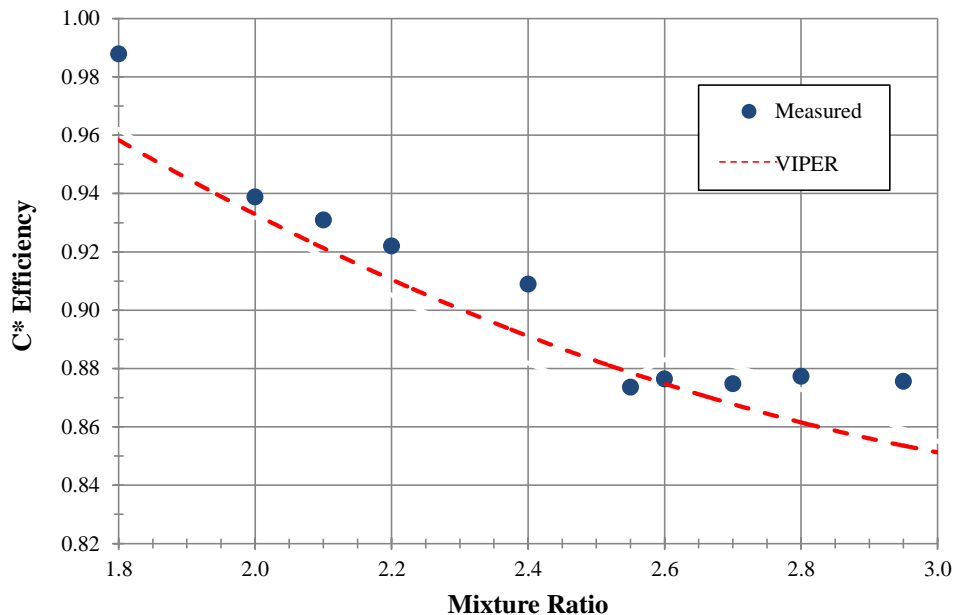

Figure 12 Comparison of predicted and measured ${ }^{4} C^{*}$ efficiency for altitude operation of the $100 \mathrm{lb}_{\mathrm{b}} \mathrm{RCE}$. Markers are data for cold to nominal inlet conditions.

American Institute of Aeronautics and Astronautics 


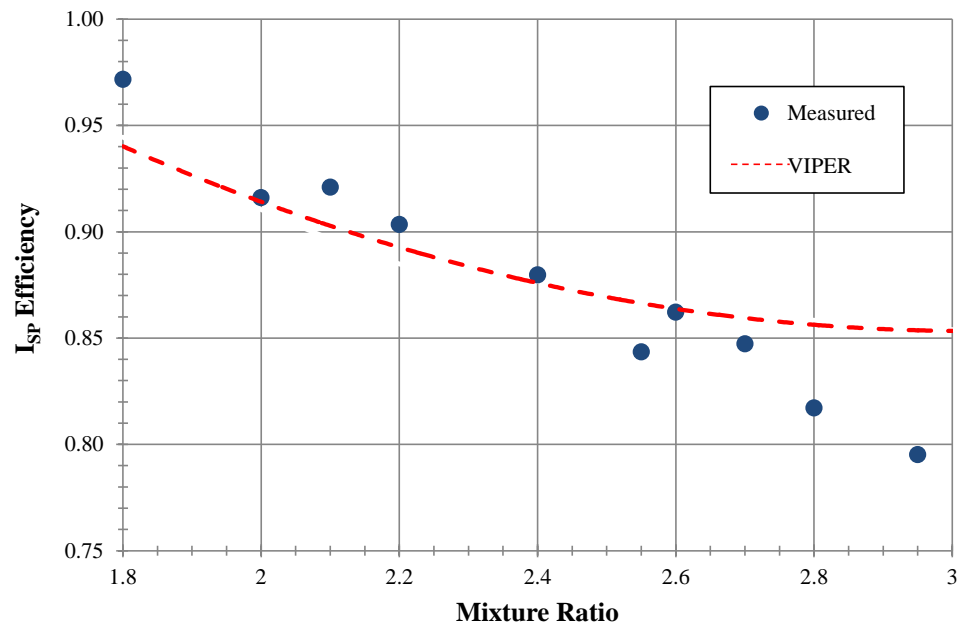

Figure 13 Comparison of predicted and measured ${ }^{4} I_{\mathrm{SP}}$ efficiency for altitude operation. Markers are data for cold to nominal inlet conditions.

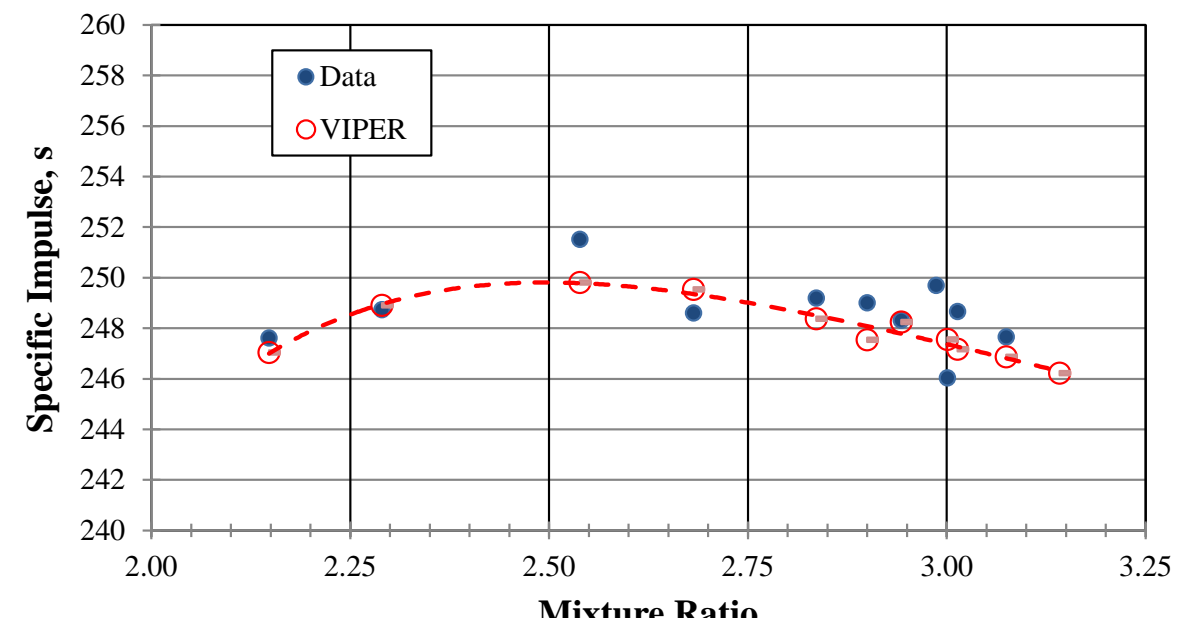

Figure 14 Comparison of predicted and measured ${ }^{8}$ sea-level specific impulse for the $5500 \mathrm{lb}_{\mathrm{f}} \mathrm{AME}$.

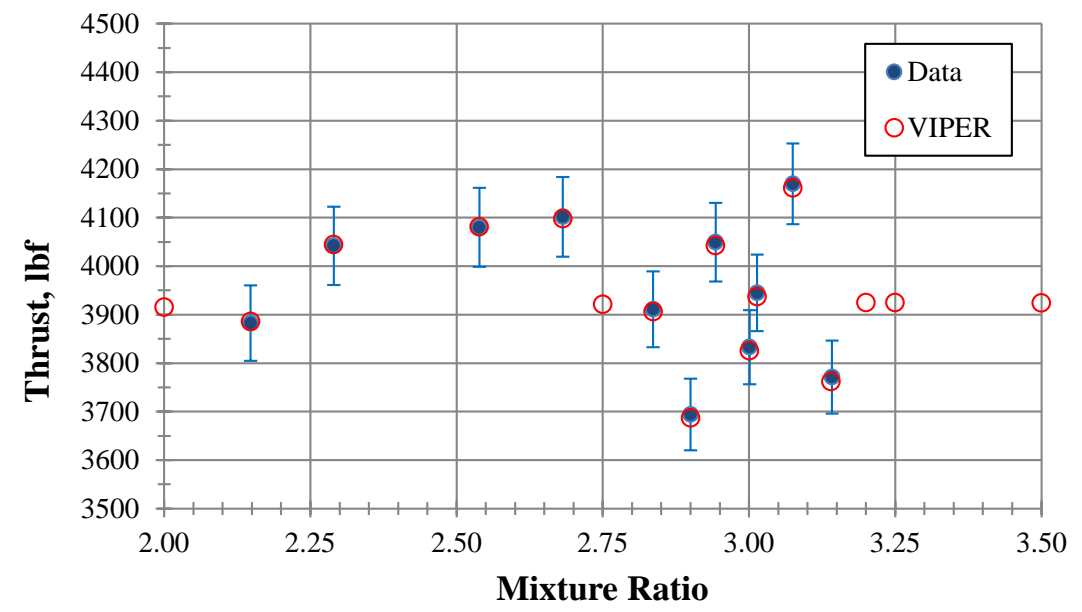

Figure 15 Comparison of predicted and measured ${ }^{8}$ thrusts for the sea-level chamber of the $5500 \mathrm{lb}_{\mathrm{f}} \mathrm{AME} . \mathrm{P}_{\mathrm{C}}$ was varied to match $P_{C}$ in the data.

19

American Institute of Aeronautics and Astronautics 


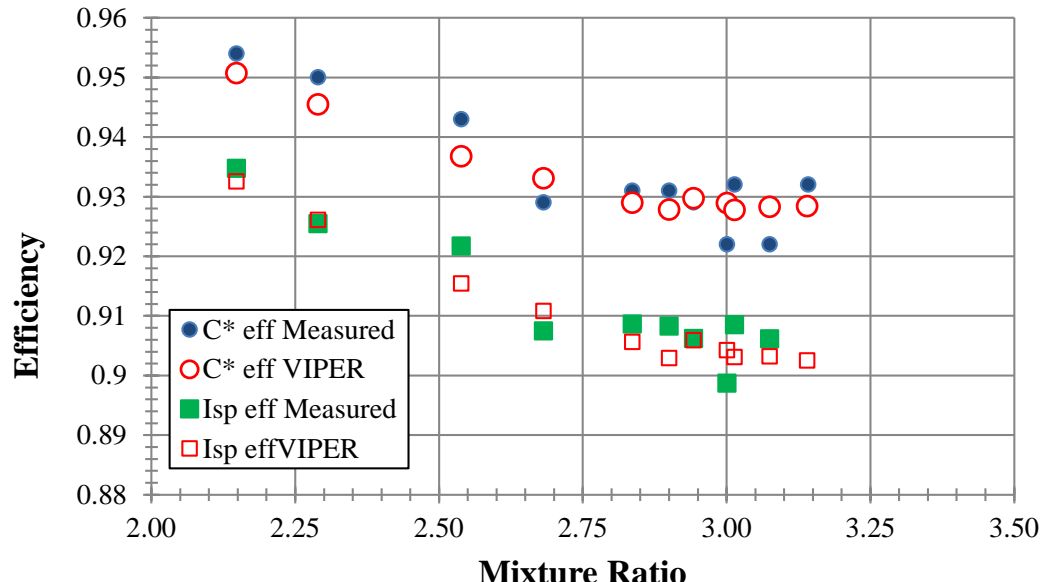

Figure 16 Comparison of predicted and measured ${ }^{8}$ Isp and $C^{*}$ efficiencies at sea-level for the $5500 \mathrm{lb}_{\mathrm{f}}$ AME.

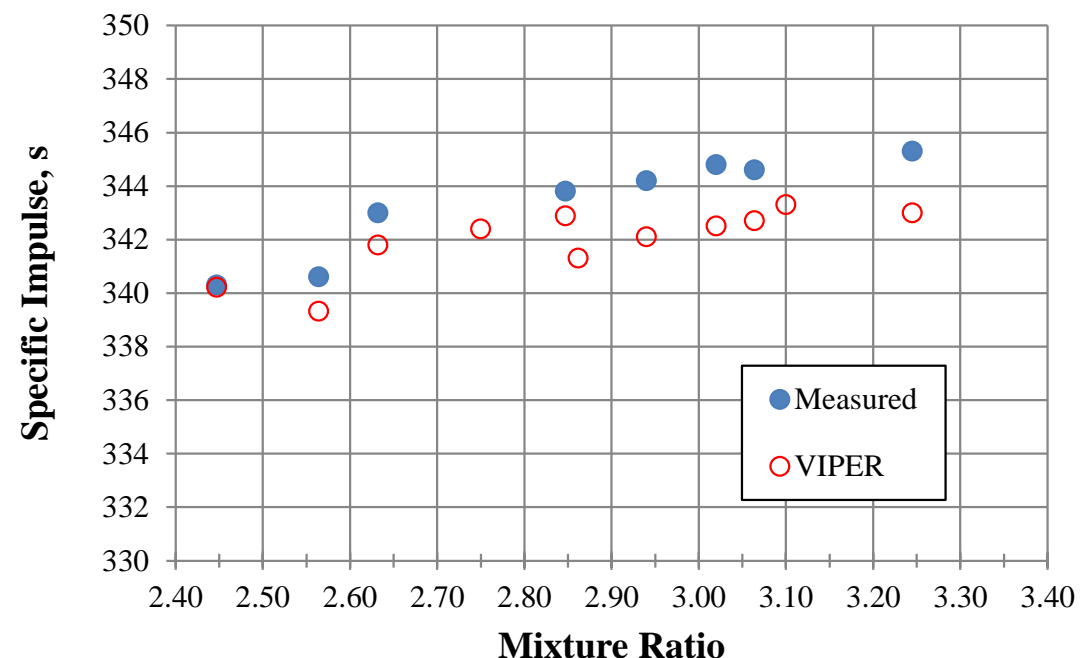

Figure 17 Comparison of predicted and measured ${ }^{9}$ specific impulse for altitude testing of the $5500 \mathrm{lb}_{\mathrm{f}}$ AME.

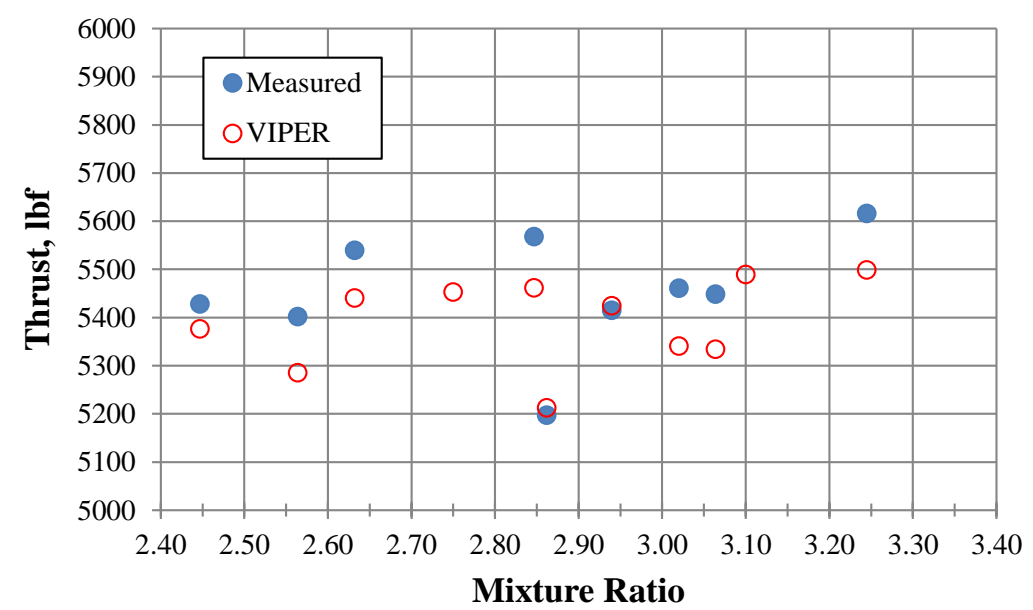

Figure 18 Comparison of predicted and measured ${ }^{9}$ thrust for altitude testing of the $5500 \mathrm{lb}_{\mathrm{f}} \mathrm{AME}$.

American Institute of Aeronautics and Astronautics 


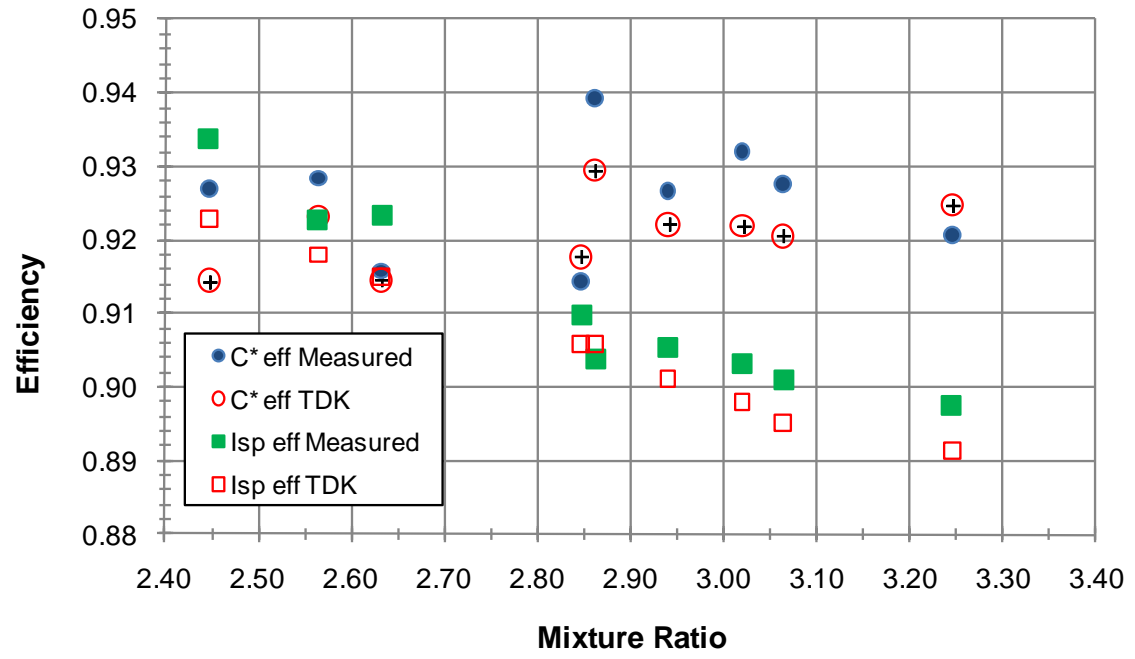

Figure 19 Comparison of predicted and measured" Isp and $C^{*}$ efficiencies of the $5500 \mathrm{lb}_{\mathrm{f}} \mathrm{AME}$. 